\title{
Unlocking the Potential of Single Atoms Loaded Geobacter Hybrid Catalyst as Bifunctional Electrocatalyst for Water Splitting
}

Srikanth Pedireddy*, Mahesh Kumar Ravva, Chandrani Nayak, Dalaver H. Anjum, Shambhu Nath Jha, Krishna P. Katuri, Pascal E. Saikaly*

Dr. S. Pedireddy, Dr. K.P. Katuri, Prof. P.E. Saikaly

Division of Biological and Environmental Science \& Engineering, Water Desalination and Reuse Center, King Abdullah University of Science and Technology, Thuwal, Saudi Arabia 23955-6900

Dr. M.K. Ravva

Department of Chemistry, SRM University AP, Andhra Pradesh, India 522502

Dr. C. Nayak, Dr. S.N. Jha

Atomic and Molecular Physics Division, Bhabha Atomic Research Centre, Trombay, Mumbai, India 400085

Dr. D.H. Anjum

Department of Physics, Khalifa University, Abu Dhabi, UAE 127788

E-mail: pascal.saikaly@kaust.edu.sa; srikanth.pedireddy@kaust.edu.sa

Keywords: single-atom catalysts, water splitting, bifunctional electrocatalyst, Geobacter sulfurreducens, extracellular electron transfer, electrochemical energy storage 
Abstract. Single-atom metal (SA-M) catalysts with high dispersion of active metal sites allow maximum atomic utilization. However, conventional synthesis of SA-M catalysts involves high-temperature treatments, leading to a low yield with random distribution of atoms. Herein, a facile method to synthesize SA-M catalysts $(\mathrm{M}=\mathrm{Fe}, \mathrm{Ir}, \mathrm{Pt}, \mathrm{Ru}, \mathrm{Cu}$, or $\mathrm{Pd})$ in a single step at ambient temperature, using the extracellular electron transfer capability of Geobacter sulfurreducens (GS), is presented. Interestingly, the SA-M is coordinated to three nitrogen (N) atoms adopting an $\mathrm{MN}_{3}$ on the surface of GS. Dry samples of SA-Ir@GS without further heat treatments show exceptionally high activity for OER when compared to benchmark $\mathrm{IrO}_{2}$ catalyst and comparable HER activity to commercial 10 wt.\% Pt/C. The SA-Ir@GS electrocatalyst exhibits the best water $\square$ splitting performance compared to other SA-M@GS, showing a low applied potential of $1.65 \mathrm{~V}$ to achieve $10 \mathrm{~mA} \mathrm{~cm}^{-2}$ in $1.0 \mathrm{M} \mathrm{KOH}$ solution with cycling over $5 \mathrm{~h}$. The density functional calculations reveal that the large adsorption energy of $\mathrm{H}_{2} \mathrm{O}$ and moderate adsorption energies of reactants and reaction intermediates for SA-Ir@GS favorably improve its activity. This nature-based facile synthesis method of SA-M at room temperature provides a versatile platform for the preparation of other transition metal SA-M catalysts for various energy-related applications by merely altering the metal precursors.

Single-atom catalysts (SACs) with atomically dispersed active metal sites possess the advantages of maximum atomic utilization, excellent selectivity, and most exposed active sites, and have been demonstrated to be a promising catalyst for various applications including oxygen reduction reaction (ORR), ${ }^{[1,2]}$ hydrogen evolution reaction (HER), ${ }^{[3]}$ oxygen evolution reaction (OER), ${ }^{[4]} \mathrm{CO}_{2}$ reduction reaction $\left(\mathrm{CO}_{2} \mathrm{RR}\right),{ }^{[5]}$ nitrogen reduction reaction $(\mathrm{NRR}),{ }^{[6]}$ organic catalysis, ${ }^{[7,8]}$ and biomedicine. ${ }^{[9]}$ Furthermore, downsizing the metal nanoparticles to the atomic level can lead to new discrete electronic states, thereby imparting unique performance. ${ }^{[10]}$. Despite the wide application window of single-atom metal (SA-M) catalysts, the natural tendency of single atoms to aggregate due to their high surface energies, makes them particularly challenging to synthesize. ${ }^{[11]}$ Several strategies have been ingeniously proposed for synthesizing SACs, including wet chemistry, atomic layer deposition (ALD), high-energy ball milling, mass-selected soft-landing, high-temperature pyrolysis of select precursors such as metal-organic frameworks (MOFs) and metal-containing complexes, etc. ${ }^{[12,13]}$ However, synthesis methods based on pyrolysis require tedious procedures and high synthesis temperature leading to high energy consumption and production costs, and they suffer from low universality especially when using MOF. ${ }^{[12-14]}$ Also, some methods suffer from high cost and low yields such as ALD or formation of nanoparticles or clusters as in wet-chemistry 
methods. ${ }^{[12,13,15]}$ Recently, an ambient synthesis strategy was developed using easily accessible bulk metals such as metal foam (e.g., iron), however, the synthesis approach cannot be generalized to all transition metals including precious metals. ${ }^{[2,13]}$ Therefore, there is a need to develop a facile and general synthesis method of SA-M catalysts at ambient temperature.

In nature, many biological proteins require metal ion cofactors to function. An excellent example is c-type cytochromes (c-Cyts), which are redox active proteins, that contain a heme cofactor with a central iron ion coordinated to four pyrrole nitrogen atoms. The heme iron allows cytochromes to perform electron transfer reactions by undergoing reduction or oxidation. In reduced heme, the iron in cytochromes usually exists as ferrous $\left(\mathrm{Fe}^{2+}\right)$ and as ferric $\left(\mathrm{Fe}^{3+}\right)$ in oxidized heme. ${ }^{[16]}$ Since cytochromes contain individual iron centers, one may argue that these biological proteins represent the early examples of single atoms. The c-Cyts play an important role in bacterial respiration especially in electroactive bacteria which allow them to utilize insoluble electron acceptors located outside their cell for respiration. For example, the electroactive bacterium Geobacter sulfurreducens possesses a vast network of multi-heme containing outer-membrane c-Cyts (OM c-Cyts), ${ }^{[17]}$ which allows them to carry out a unique respiratory pathway, namely extracellular electron transfer (EET) pathway by coupling the oxidation of substrates (electron donor) in their cytoplasm with the reduction of insoluble electron acceptors (e.g., electrodes, metal ions) located outside their cell for respiration. ${ }^{[18]} G$. sulfurreducens (GS) possesses the highest number of genes encoding for c-Cyts (111 in the whole genome) and they assimilate more iron into their cell for synthesizing c-Cyts required for EET mechanism. ${ }^{[19]}$ The EET capability of GS prompted their selection as a target bacterium for practical biotechnological applications in microbial electrochemical systems for wastewater treatment with concomitant energy generation, ${ }^{[20,21]}$ bioremediation, ${ }^{[22]}$ bioelectronics, ${ }^{[23]}$ and synthesis of electrocatalysts. ${ }^{[18,24]}$

Herein, we report the first nature-based facile synthesis method of a wide range of highly dispersed atomically precise SA-M catalysts $(\mathrm{M}=\mathrm{Fe}, \mathrm{Ir}, \mathrm{Pt}, \mathrm{Ru}, \mathrm{Cu}$, or $\mathrm{Pd})$ in a single step at ambient temperature, using the EET capability of GS. The GS cells utilized OM c-Cyts to transfer metabolically generated electrons from the oxidation of acetate (electron donor) to reduce metal ions present outside the outer membrane of the cell (Figure 1), thus successfully coordinating and stabilizing the SA-M entity. Moreover, GS can act as a support and source for heteroatom doping. ${ }^{[18]}$ It should be noted that GS is not capable of synthesizing soluble electron shuttles such as phenazines, flavines, quinones, etc., and the only means of EET is through the expressed membrane-bound c-Cyts. ${ }^{[25]}$ Our detailed study showed that diverse SA-M@GS, where $\mathrm{M}$ is $\mathrm{Ir}, \mathrm{Pt}, \mathrm{Ru}, \mathrm{Cu}$, or $\mathrm{Pd}$, adopt an identical $\mathrm{MN}_{3}$ species with same local atomic 
coordination implanted on the surface of GS via reduction of metal precursors as revealed by comprehensive analyses of X-ray absorption near-edge structure (XANES) and extended X-ray absorption fine structure (EXAFS), and imaging by high-angle annular dark-field scanning transmission electron microscope (HAADF-STEM). Our biological approach could produce SA-M catalysts with metal loadings as high as $\sim 1 \mathrm{wt}$. \%. Considering the importance of water splitting, which is a key process in solar fuel production, rechargeable metal-air batteries, and microbial electrosynthesis of chemicals and fuels from $\mathrm{CO}_{2},{ }^{[18,}{ }^{26]}$ the electrocatalytic efficiencies of various SA-M@GS were evaluated directly for both HER and OER, upon drying without further heat treatments such as pyrolysis or hydrothermal approaches, with the SAIr@GS containing 1wt. \% Ir demonstrated outstanding performance as a bifunctional catalyst. Moreover, the SA-Ir@GS also demonstrated good overall water splitting performance in 1m $\mathrm{KOH}$, operating with reasonable stability as both cathode and anode. Further, the unique structure, composition, low coordination, and exposed active sites of SA-M@GS showed enhanced activity and durability when benchmarked with commercial $10 \% \mathrm{Pt} / \mathrm{C}$ and $\mathrm{IrO}_{2}$ electrocatalysts under the same testing conditions.

First, we confirmed the formation of SA-Fe@GS by growing an active culture of GS using acetate as electron donor and fumarate as electron acceptor. The GS cells were killed by ethanol, dried overnight in vacuum dryer, and SA-Fe@GS was then subjected to various characterizations (Figure 2) to understand its physiochemical properties. The main source of Fe in SA-Fe@GS was from heme-containing cytochromes expressed by GS. Scanning electron microscopy (SEM) images of SA-Fe@GS revealed a crumpled morphology with many grooves on the surface (Figure 2a), creating a high area surface to facilitate the reactions.

Transmission electron microscopy (TEM) image (inset in Figure 2a) and high-angle annular dark-field scanning transmission electron microscopy (HAADF-STEM) image (Figure 2b) demonstrated that there were no observable Fe clusters/nanoparticles on GS surface. Aberration corrected HAADF-STEM images revealed individual Fe atoms highlighted by red circles on the surface of GS (Figure 2b). This supports the presence of atomically dispersed Fe species from the expression of heme-containing cytochromes by GS. ${ }^{[27]}$ We hypothesized that these single-atom Fe centers will subsequently serve as anchoring sites for the formation of SA-M $(\mathrm{M}=\mathrm{Ir}, \mathrm{Ru}, \mathrm{Pt}, \mathrm{Cu}$ or $\mathrm{Pd})$ of desired chemical identity. Hence, we estimated the content of $\mathrm{Fe}$ on the surface of SA-Fe@GS catalyst to be 1.3 wt.\%, as confirmed by energy dispersive X-ray (EDX) analysis (Figure 2e). The Fe content determined herein served as a basis for the loading of different transition metals to achieve SA-M dispersion. The X-ray diffraction (XRD) pattern of SA-Fe@GS exhibited only two broad peaks at $9^{\circ}$ and $19.4^{\circ}$, and no crystalline peaks 
corresponding to $\mathrm{Fe}, \mathrm{Fe}_{2} \mathrm{O}_{3}$ and $\mathrm{Fe}_{3} \mathrm{O}_{4}$ were observed (Figure S1, Supporting Information), further confirming the exclusion of clusters/nanoparticles of Fe. Additionally, the STEM-EDX elemental mapping of SA-Fe@GS confirmed the well dispersed Fe on the surface of GS (Figure 2d). To investigate the local structure of SA-Fe@GS, X-ray absorption fine structure (EXAFS) measurements were performed (Figure S2, Supporting Information). The absorption edge of Xray absorption near-edge structure (XANES) spectroscopy of SA-Fe@GS was situated between those of $\mathrm{Fe}$ foil and $\mathrm{Fe}_{2} \mathrm{O}_{3}$ reference (Figure $\mathrm{S} 2 \mathrm{a}$, Supporting Information), suggesting that the single-atom Fe carries a positive charge $(+3)$ (Figure $2 b)$. Fourier-transformation (FT)-EXAFS spectra of SA-Fe@GS only presents a distinct peak for $\mathrm{Fe}-\mathrm{N}$ coordination at $1.46 \AA$, and absence of $\mathrm{Fe}-\mathrm{Fe}$ scattering signal at $\sim 2.17 \AA$, which clearly confirms that $\mathrm{Fe}$ atoms are atomically dispersed and coordinated to N (Figure 2c). Furthermore, FT-EXAFS fitting was performed to determine the structural and coordination information of $\mathrm{Fe}$ atoms. The coordination structure around Fe single atoms in SA-Fe@GS was evaluated by fitting the experimental $\chi(r)$ versus $r$ data from 1-2.5 $\AA$ assuming Fe-N, Fe-S and Fe-C co-ordination shells. Fe exhibits a first shell Fe-N at $2.01 \AA$ with coordination number 4, while $\mathrm{Fe}-\mathrm{S}$ interaction is located at $2.21 \AA$ with coordination number 1 , and Fe-C at $2.45 \AA$ with coordination number 3 (Figure S3a,c, Supporting Information). The R factor of the fitting was 0.003, which suggests a good fitting.

After confirming the formation of SA-Fe@GS , different metal cations $\left(\mathrm{M}^{\mathrm{n}+}, \mathrm{M}=\mathrm{Ir}, \mathrm{Ru}, \mathrm{Pt}\right.$, $\mathrm{Cu}$ or $\mathrm{Pd}$ ) were introduced separately as electron acceptors into the growth media containing acetate (electron donor) but no fumarate (Figure 1) to test the generality of the synthesis method, forming a series of SA-M@GS. Based on the Fe content of GS cells, we added 1 wt.\% of the desired metal precursors assuming single-atom Fe of heme-containing cytochromes are the only center for the metal reduction. The addition of $1 \mathrm{wt}$ \% of metal precursors exclusively resulted in the formation of atomic dispersion while higher wt.\% of metal precursors formed clusters/metal nanoparticles on the surface of the GS cells (data not shown). The expression of heme-containing cytochromes in GS can be greatly amplified by increasing the amount of $\mathrm{Fe}^{2+}$ in the media composition. As a result of over expression of cytochromes, the wt.\% of Fe in the GS cells increase, which will further allow more wt.\% loading of SA-M. For example, it is clearly visible (Figure S4, Supporting Information) that the GS cells supplied with $2 \mathrm{mg}$ of $\mathrm{Fe}^{2+}$ in the growth media by maintaining all other conditions are intensely red when compared to 0.2 $\mathrm{mg}$ of $\mathrm{Fe}^{2+}$, indicating the over expression of cytochromes. SEM and scanning transmission electron microscopy (STEM) images demonstrate that there are no visible Ir particles in the prepared SA-Ir@GS (Figure S5, Supporting Information). The images taken by aberration- 
corrected HAADF-STEM revealed the presence of high density of individual Ir atoms (Figure 3a), which were clearly visible from the significant difference in $\mathrm{Z}$ contrasts of the image for Ir and GS. The content of Ir was quantified to be $0.18 \mathrm{mg}$ in $20 \mathrm{mg}$ of SA-Ir@GS (i.e., $\sim 1$ wt. \%) as confirmed by ICP $\square$ MS. To confirm that the metal cations were reduced into individual metal (M) atoms by the metabolically generated electrons from the oxidation of acetate inside the cell and which are then transferred by OM c-Cyts to the surface to reduce the metal cations, we conducted a control experiment by excluding acetate from the media. Ir cations were chosen for this control experiment since it is a heavier atom, thus making it easy to visualize under STEM to see if there are any secondary processes such as adsorption. In the absence of acetate, bright dots of Ir atoms were absent on the GS surface as confirmed by HAADF-STEM images (Figure S6, Supporting Information). This observation supports that the metabolically generated electrons from the oxidation of acetate were involved in the reduction of $\mathrm{Ir}^{+3}$.

The STEM-EDX elemental mapping of SA-Ir@GS revealed a uniform distribution of the elements C, N, Fe, and Ir over the entire GS cell (Figure S7, Supporting Information). The regional EDX analysis on SA-Ir@GS illustrated that the isolated Ir atoms are present on Feentity rather than other components of GS, which suggests that coordination and reduction occurred at the iron center.

Additional confirmation of atomic dispersion of Ir was demonstrated by performing EXAFS (Figure 3b) and XANES measurements (Figure S8a, Supporting Information) for SA-Ir@GS. The oxidation state of Ir was calculated by the intensity of the white line at the $\mathrm{Ir} \mathrm{L}_{3}$-edge in XANES spectra. The Ir XANES results show that the white line intensity of SA-Ir@GS (Figure S8a, Supporting Information) is close to that of Ir foil reported in the literature ${ }^{[28]}$, indicating that the average oxidation state of Ir is mostly zero. The FT-EXAFS for both SA-Ir@GS and commercial $\mathrm{IrO}_{2}$ showed a single prominent peak located at $1.8 \AA$ ( Ir-N) and $1.5 \AA$ (Ir-O) respectively (Figure 3b), while Ir foil has been reported to have a major peak at $2.6 \AA$ corresponding to the $\operatorname{Ir} \square \operatorname{Ir}$ bond ${ }^{[28]}$. The lack of a peak at $2.6 \AA$ (Ir-Ir bond) in the SA-Ir@GS spectrum supports the atomic dispersion of Ir.

The SA-Ir@GS was further analyzed by X-ray photoelectron spectroscopy (XPS) to obtain information on surface composition and valence state (Figure S9a, Supporting Information). The fitting of the XPS spectra of $\operatorname{Ir} 4 \mathrm{f}$ revealed the existence of reduced $\operatorname{Ir}(0)$ along with $\operatorname{IrO}{ }_{2}$ and $\mathrm{IrO}_{3}$. The over oxidation of the Ir was observed due to the extended storage of the samples before XPS analysis. The XRD pattern of SA-Ir@GS sample was very similar to that of SAFe@GS, displaying only two peaks at $9^{\circ}$ and $19.4^{\circ}$, which are typical of amorphous carbon (Figure S9b, Supporting Information). No other crystalline metal phases were observed in the 
XRD of SA-Ir@GS, further supporting the lack of Ir nanoclusters/nanoparticles with Ir-Ir stacking on GS surface, consistent with the STEM analysis (Figure 3a). All the above detailed characterizations support the successful synthesis of atomically dispersed Ir over the surface of GS cells.

X-ray Absorption Spectroscopy (XAS) studies were performed on SA-Ir@GS to probe the local coordination structure around the single metal Ir on the surface of GS (Figure 4). Subsequently, ab-initio studies were performed to check the stability of the structure. The FTEXAFS data was fitted to get coordination information and atomic configuration around Ir atom. The coordination structure around Ir single atoms in SA-Ir@GS was evaluated by fitting the experimental $\chi(r)$ versus $r$ data from 1-2.5 $\AA$ (Figure $4 \mathrm{a}$ ) assuming Ir-N, Ir-Fe and Ir-C coordination shells. The Ir single atoms on GS form $\mathrm{IrN}_{3}$ moiety and are linked to Fe of the hemecontaining cytochromes. Ir exhibits a first shell Ir-N at $2.11 \AA$ with coordination number 3 , while Ir-Fe interaction is located at $2.31 \AA$ with coordination number 1 , and Ir-C at $2.54 \AA$ with coordination number 7 (Figure 4c). The R factor of the fitting was 0.006 , which suggests good fitting.

Most notably, the facile synthesis approach reported here is versatile and can be applied to synthesize other atomically dispersed transition metals, including $\mathrm{Pt}, \mathrm{Cu}, \mathrm{Ru}$, and $\mathrm{Pd}$. This is possible because OM c-Cyts are complex molecules with a wide range of potentials due to the presence of multiheme molecules. Each heme in a multiheme cytochrome possess definite redox potential which will affect the neighboring hemes creating a wide potential window. The midpoint potential of OM c-Cyts involved in EET is mostly in the range of -0.15 to $-0.2 \mathrm{~V}$ vs. SHE, which is much lower when compared to metal ions discussed in this manuscript. ${ }^{[29]}$. This was demonstrated by using metal precursors of Pt, $\mathrm{Ru}, \mathrm{Cu}$, and Pd to synthesize SA-Pt@GS, SA-Ru@GS, SA-Cu@GS, and SA-Pd@GS, respectively. A noticeable change in the color of the solutions was observed depending on the identity of the metal reduced on the surface of GS (Figure S10, Supporting Information). The strong contrast of individual atoms of $\mathrm{Pt}(\sim 1 \mathrm{wt} . \%$, SA-Pt@GS), Ru (1 wt. \%, SA-Ru@GS), Pd (1 wt. \%, SA-Pd@GS), and Cu (1 wt. \%, SA$\mathrm{Cu} @$ GS) were finely dispersed on GS surface without visible particles (Figure 3c-f, Figure S11, Supporting Information). FT-EXAFS analysis of all these specimens also revealed the existence of single atoms (Figure 3h-j), and the adsorption edge of SA-Ms was higher than the related metal foil, suggesting that the metal atoms in SA-M@GS was carrying a positive charge (Figure S8, Supporting Information). The XRD spectra of all these samples (Figure S12, Supporting Information) were consistent with SA-Ir@GS showing only two peaks at $9^{\circ}$ and $19.4^{\circ}$, confirming the lack of metal agglomeration in $\mathrm{Pt}, \mathrm{Ru}, \mathrm{Pd}$, and $\mathrm{Cu}$ containing samples. Similar 
to SA-Ir@GS, oxidized valence states along with metallic state were also observed in the XPS analysis of SA-Pt@GS, SA-Ru@GS, SA-Cu@GS, and SA-Pd@GS (Figure S13, Supporting Information). Based on EXAFS data and DFT stability studies, we derived the optimized geometries of SA-Pt@GS, and SA-Ru@GS (Figure S14, Supporting Information) where the SA-M on GS forms $\mathrm{MN}_{3}$ (where $\mathrm{M}=\mathrm{Pt}, \mathrm{Ru}, \mathrm{Cu}$, and $\mathrm{Pd}$ ) moiety and are linked to $\mathrm{Fe}$ of the heme-containing cytochromes. We envisage that this stable coordination of three nitrogen around the metal will stabilize the catalyst from aggregation during the catalytic reactions.

After meticulous characterization of SA-M@GS, their electrocatalytic OER and HER performance were evaluated using a standard three $\square$ electrode cell at $30^{\circ} \mathrm{C}$ in $\mathrm{N}_{2} \square$ saturated $1.0 \mathrm{M} \mathrm{KOH}$ solution. As a reference point, we also performed HER and OER measurements using commercial $10 \%$ Pt-coated carbon $(\mathrm{Pt} / \mathrm{C})$ and $\mathrm{IrO}_{2}$ under the same conditions. The SAFe@GS was used as a control for comparison as it represents only G. sulfurreducens without any external metal precursors added. The linear $\square$ sweep voltammetry (LSV) curve of SAIr@GS recorded at $5 \mathrm{mV} \mathrm{s}^{-1}$ demonstrated an early onset overpotential of $283 \mathrm{mV}$ for generating high HER current density $\left(10 \mathrm{~mA} \mathrm{~cm}^{-2}\right)$, and had a similar LSV curve to commercial $\mathrm{Pt} / \mathrm{C}$, which requires $257 \mathrm{mV}$ to deliver $10 \mathrm{~mA} \mathrm{~cm}^{-2}$ (Figure 5a) and is comparable to most HER catalysts (Table S2, Supporting Information). The overpotentials ( $\eta$ ), presented in decreasing order, to reach HER current density of $10 \mathrm{~mA} \mathrm{~cm}^{-2}$ were as follows: SA-Ru@GS < SA-Fe@GS < SA-Pt@GS < SA-Ir@GS < 10 \% Pt/C, indicating that SA-Ir@GS had the best HER performance compared to the other SA-M@GS. The Tafel slopes (Figure 5b) resulting from the LSV curves for HER (Figure 5a), showed that SA-Ir@GS had the lowest Tafel slope (88.4 mV dec ${ }^{-1}$ ) when compared to SA-Pt@GS (106 mV dec $\left.{ }^{-1}\right)$, SA-Ru@GS (114 mV dec $\left.{ }^{-1}\right)$, and SA-Fe@GS $\left(110 \mathrm{mV} \mathrm{dec}^{-1}\right)$. Low Tafel slopes are an indication of high performance HER electrocatalyst activity. The Tafel slope is often utilized to indicate the electrochemical HER mechanism. The Tafel slope should be 120 , 40, or $30 \mathrm{mV} \mathrm{dec}{ }^{-1}$ if Volmer (or discharge), Heyrovsky (or electrochemical desorption), or Tafel (or recombination) reaction is the ratelimiting step of the HER. ${ }^{[20]}$ The SA-Ir@GS electrocatalyst, in particular demonstrated a lower Tafel slope than commercial 10\% Pt/C (128 mV dec $\left.{ }^{-1}\right)$, indicating favorable HER kinetics under alkaline conditions via a Volmer $\left(40 \mathrm{mV} \mathrm{dec}^{-1} ; \mathrm{H}_{2} \mathrm{O}+\mathrm{e}^{-} \rightarrow \mathrm{H}^{*}+\mathrm{OH}^{-}\right)-$Heyrovsky (120 $\mathrm{mV} \mathrm{dec}{ }^{-1} ; \mathrm{H}_{2} \mathrm{O}+\mathrm{H}^{*}+\mathrm{e}^{-} \rightarrow \mathrm{H}_{2}+\mathrm{OH}^{-}$) pathway.

Similarly, the LSV curves for OER demonstrated superior electrocatalytic activity with SAIr@GS (Figure 5c). The overpotentials, presented in decreasing order, to deliver current density of 10 mA cm ${ }^{-2}$ were as follows: SA-Fe@GS $(480$ mV)<SA-Pt@GS $(470$ mV)<SA-Ru@GS $(438 \mathrm{mV})<\mathrm{IrO}_{2}(420 \mathrm{mV})<\mathrm{SA}-\mathrm{Ir} @$ GS $(418 \mathrm{mV})$. Also, SA-Ir@GS showed the lowest Tafel 
slope of $57.2 \mathrm{mV} \mathrm{dec}{ }^{-1}$, compared to SA-Pt@GS (63.5 mV dec $\left.{ }^{-1}\right)$, SA-Ru@GS (64.4 $\left.\mathrm{mV} \mathrm{dec}{ }^{-1}\right), \mathrm{IrO}_{2}\left(75.9 \mathrm{mV} \mathrm{dec}^{-1}\right)$, and SA-Fe@GS (134.8 $\mathrm{mV} \mathrm{dec}^{-1}$ ) (Figure 5d), indicating that SA-Ir@GS has excellent OER kinetics, superior to the benchmark OER catalyst (i.e., $\mathrm{IrO}_{2}$ ), possibly due to its high exchange current density (Table S3, Supporting Information). The exchange current density is a key parameter of the interfacial reaction kinetics. ${ }^{[30]}$ The exchange current density for SA-Ir@GS $\left(0.29 \mathrm{~mA} \mathrm{~cm}^{-2}\right)$ was the highest compared to the other SA-Ms: SA-Pt@GS $\left(2.4 \times 10^{-4} \mathrm{~mA} \mathrm{~cm}^{-2}\right)$, SA-Ru@GS $\left(0.045 \mathrm{~mA} \mathrm{~cm}^{-2}\right)$, and SA-Fe@GS $\left(8 \times 10^{-7}\right.$ mA cm $\left.{ }^{-2}\right)$. Notably, SA-Ir@GS demonstrated similar OER kinetics as commercial $\mathrm{IrO}_{2}(0.32$ $\mathrm{mA} \mathrm{cm}^{-2}$ ).

Several SA-M catalysts containing $\mathrm{MNC}$ (where $\mathrm{M}=\mathrm{Fe}, \mathrm{Mo}, \mathrm{Cu}, \mathrm{Mn}, \mathrm{Ir}$, and $\mathrm{Pt}$ ) structure have been demonstrated for OER and HER catalysis. However, most of these electrocatalysts can only have a single function, that is they function as HER or OER. ${ }^{[31,32]}$ For practical water splitting applications, both HER and OER must be carried out in the same electrolyte (alkaline solution). The SA-Ir@GS had a lower total overpotential (701 mV combining HER and OER) than the other SA-Ms (Figure 5e), suggesting that it can be applied as an effective bifunctional catalyst for water splitting. Therefore, we loaded SA-Ir@GS catalyst on graphitic sheets (1 $\mathrm{cm} \times 1 \mathrm{~cm}$ ) as anode and cathode in $1.0 \mathrm{M} \mathrm{KOH}$ and a current density of $10 \mathrm{~mA} \mathrm{~cm}^{-2}$ could be attained with a cell potential of only $1.65 \mathrm{~V}$ (Figure 5f), which is comparable to reported catalysts (Table S4, Supporting Information). Further, the SA-Ir@GS catalyst demonstrated stable long $\square$ term $(5 \mathrm{~h}$ ) overall water splitting via electrolysis at a constant voltage of $1.65 \mathrm{~V}$ (Figure S15, Supporting Information). Stability of SA-Ir@GS is possible due to the stable $\mathrm{MN}_{3}$ coordination which prevents aggregation. ${ }^{[7]}$ According to Figure 5e, the total overpotential of SA-Ir@GS (701 mV) was comparable to the total overpotential $(677 \mathrm{mV})$ of commercial $10 \%$ $\mathrm{Pt} / \mathrm{C}$ for HER and $\mathrm{IrO}_{2}$ for OER. Further, these results confirm that SA-Ir@GS can act as a bifunctional electrocatalyst, which is more practical for alkaline water splitting since it replaces the need for fabricating two different electrocatalysts.

The unique configuration of SA-Ir@GS detected by XANES and XPS would contribute to a discrete electronic structure which is different from bulk metallic Ir and Ir oxides, which inevitably influence the adsorption of reactants and intermediates in OER and HER eventually enhancing their electrocatalytic performance as discussed below. DFT calculations were performed to gain more insights on the energetics of OER and HER. The performance of OER and HER was studied in two different model systems. One is isolated Fe(III)-porphyrin molecule, and another is SA-Ms (where $\mathrm{M}=\mathrm{Pt}$, Ru, Ir) loaded on Fe(III)-porphyrin molecule. Since HER and OER occur in the presence of the protein environment, the SA-Ms are bound 
with three ammonia $\left(\mathrm{NH}_{3}\right)$ neutral ligands to mimic the protein environment. It can be clearly seen from the optimized geometries that the SA-Ms are adsorbed on the porphyrin ring (Figure 4 and Figure S3, S14, Supporting Information). As these complexes contain two open-shell metals, we have fully explored the different multiplicities in each case and considered the energetically most stable electronic configurations (details provided in Supplementary Information). The DFT calculations for both OER and HER using the model systems are presented below.

The DFT calculations on SA-M@GS indicated that the catalytic reaction path and activity of OER is strongly dependent on the identity of the metal in SA-M@GS. The OER energy diagram was calculated using DFT at potentials of $0 \mathrm{~V}$ and $1.23 \mathrm{~V}$ for the various SA-M@GS by following the suggested OER pathways as presented in Figure 6a,b. The reaction limiting step serves as a descriptor to evaluate the catalytic activity of the catalyst, which can be obtained from the Gibbs free energy of the rate limiting step. At $U=0 \mathrm{~V}$, the rate limiting step for SAFe@GS was the formation of $\mathrm{OH}^{*}$ with a limiting barrier as large as $2.33 \mathrm{eV}$. For SA-Ir@GS, and SA-Pt@GS, the rate limiting step was the formation of $\mathrm{O}^{*}$ from $\mathrm{OH}^{*}$ with limiting barriers of $1.88 \mathrm{eV}, 2.03 \mathrm{eV}$, and $2.95 \mathrm{eV}$, respectively. In the case of SA-Ru@GS, the oxidation of $\mathrm{O}^{*}$ to $\mathrm{OOH}^{*}$ was the rate limiting step. The $\mathrm{O}_{2}$ desorption from the active sites is the last step in OER, and its energy barrier was largest for SA-Fe@GS (3.55 eV), followed by SA-Ru@GS (1.63 eV), SA-Pt@GS (1.52 eV), and SA-Ir@GS (1.39 eV).

At $\mathrm{U}=1.23 \mathrm{eV}$, the formation of $\mathrm{OH}^{*}$ (first step) on SA-Fe@GS was still limiting with a barrier of 1.1 eV, whereas the first step on SA-Ir@GS, SA-Pt@GS, and SA-Ru@GS, had a negative Gibbs free energy and occurs spontaneously. Additionally, the energies of the intermediates $\left(\mathrm{O}^{*}, \mathrm{OOH}^{*}\right.$, and $\left.\mathrm{O}_{2}{ }^{*}\right)$ on SA-Fe@GS were more negative when compared to the other SA-M@GS. This infers that the chemical interaction of SA-Fe@GS with the intermediates was strong and possess high energy barriers for the evolution of oxygen. Among the SA-M@GS electrocatalysts reported here, DFT calculations showed that SA-Ir@GS has small energy barriers between the reactants and products. These results support its superior OER electrocatalytic activity compared to the other SA-M@GS electrocatalysts (Figure 5c,d).

As discussed in previous studies, various descriptors of HER activity are proposed to understand the efficiency of electrocatalysts. In the current study, we used the water dissociation process as the descriptor for estimating the efficiency of SA-M@GS electrocatalysts ${ }^{[31,33]}$. The water dissociation reaction on metal centers in Fe(III)-porphyrin and SA-Ms (where $\mathrm{M}=\mathrm{Ru}$, Ir) loaded on Fe(III)-porphyrin molecule was modeled to estimate the energy barrier for HER. Model predictions revealed that water has the largest adsorption energy 
on SA-Ir@GS (0.92 eV) and lowest on SA-Fe@GS (0.08 eV) (Figure 6c). Furthermore, less energy is required to dissociate water molecule when water is adsorbed on SA-Ir@GS (Figure 6d). The DFT calculations further indicated that the water dissociation process in the case of SA-Ir@GS is exothermic in nature while that of pristine Fe(III)-porphyrin (i.e., SA-Fe@GS) is endothermic. Based on the DFT results, we can conclude that water prefers to dissociate on Ir atoms more than Fe(III) atoms, and SA-Ir@GS is a better HER electrocatalyst than SA-Fe@GS and other SA-M@GS, further supporting its superior HER electrocatalytic activity based on LSV (Figure 5a,b).

In summary, $\mathrm{SA}-\mathrm{M}(\mathrm{M}=\mathrm{Ir}, \mathrm{Ru}, \mathrm{Pt}, \mathrm{Cu}$ or $\mathrm{Pd})$ supported $\mathrm{GS}$ were synthesized at room temperature. We identified that the SA-Ms adopted an $\mathrm{MN}_{3}$ configuration with $\mathrm{M}$ linked to $\mathrm{Fe}$ on heme-containing cytochromes using a combination of EXAFS, XANES, STEM imaging, and DFT analysis. SA-M@GS demonstrated bifunctional electrocatalytic activities towards HER and OER, with SA-Ir@GS showing superior OER and HER electrocatalytic activity compared to the other SA-M@GS electrocatalysts. SA-Ir@GS demonstrated an overpotentials of $283 \mathrm{mV}$ and $418 \mathrm{mV}$ to achieve current densities of $10 \mathrm{~mA} \mathrm{~cm}^{-2}$ in $1 \mathrm{M} \mathrm{KOH}$ for HER and OER, respectively. Moreover, SA-Ir@GS was integrated to perform overall water splitting at an applied potential of $1.65 \mathrm{~V}$ vs. RHE, which is lower than commercial $\left(10 \% \mathrm{Pt} / \mathrm{C}\right.$ and $\left.\mathrm{IrO}_{2}\right)$ and most reported catalysts, to achieve a current density of $10 \mathrm{~mA} \mathrm{~cm}^{-2}$. The electrocatalytic performance of SA-M@GS may be further improved by increasing the cytochrome expression in GS by altering the growth conditions and thus the density of single atom sites. Our study outlines an efficient biological approach to achieve a $\mathrm{MN}_{3}$ type $\mathrm{SA}-\mathrm{M}$ catalyst supported on $\mathrm{GS}$ that can be used for various electrocatalytic applications including OER, HER, ORR, $\mathrm{CO}_{2}$ and $\mathrm{N}_{2}$ reductions. Also, our work can inspire the use of other efficient electroactive bacteria for synthesizing high-performing and low-cost electrocatalysts for various energy-related applications. Taking into consideration the cost of raw chemicals only, the estimated cost to synthesize 1g of SA-Ir@GS catalyst is 3.81 euros compared to 13.6 euros for 1g of 1 wt.\% Ir/C (38330.06; Alfa Aesar) using conventional methods such as impregnation followed by reduction (Figure S16, Supporting Information).

\section{Supporting Information}

Supporting Information is available from the Wiley Online Library or from the author.

\section{Acknowledgements}


This work was supported by Competitive Research Grant (URF/ 1/2985-01-01) from King Abdullah University of Science and Technology to PES. Authors thank synchrotron facility at the Raja Ramanna Centre for Advanced Technology (RRCAT), Indore, India. Authors are thankful to KAUST Supercomputing Core Lab.

\section{Conflict of interest}

The authors declare no conflict of interest.

Received: ((will be filled in by the editorial staff))

Revised: ((will be filled in by the editorial staff))

Published online: ((will be filled in by the editorial staff))

[1] A. Han, W. Chen, S. Zhang, M. Zhang, Y. Han, J. Zhang, S. Ji, L. Zheng, Y. Wang, L. Gu, C. Chen, Q. Peng, D. Wang, Y. Li, Adv. Mater. 2018, 30, 1706508; Y. Lin, P. Liu, E. Velasco, G. Yao, Z. Tian, L. Zhang, L. Chen, Adv. Mater. 2019, 31, 1808193; X. X. Wang, D. A. Cullen, Y.-T. Pan, S. Hwang, M. Wang, Z. Feng, J. Wang, M. H. Engelhard, H. Zhang, Y. He, Y. Shao, D. Su, K. L. More, J. S. Spendelow, G. Wu, Adv. Mater. 2018, 30, 1706758.

[2] Y. Qu, L. Wang, Z. Li, P. Li, Q. Zhang, Y. Lin, F. Zhou, H. Wang, Z. Yang, Y. Hu, M. Zhu, X. Zhao, X. Han, C. Wang, Q. Xu, L. Gu, J. Luo, L. Zheng, Y. Wu, Adv. Mater. 2019, 31, 1904496.

[3] Q. He, D. Tian, H. Jiang, D. Cao, S. Wei, D. Liu, P. Song, Y. Lin, L. Song, Adv. Mater. 2020, 32, 1906972. [4] Y. Pan, S. Liu, K. Sun, X. Chen, B. Wang, K. Wu, X. Cao, W. C. Cheong, R. Shen, A. Han, Z. Chen, L. Zheng, J. Luo, Y. Lin, Y. Liu, D. Wang, Q. Peng, Q. Zhang, C. Chen, Y. Li, Angew. Chem. Int. Ed. Engl. 2018, $57,8614$.

[5] Y. Cheng, S. Zhao, B. Johannessen, J.-P. Veder, M. Saunders, M. R. Rowles, M. Cheng, C. Liu, M. F. Chisholm, R. De Marco, H.-M. Cheng, S.-Z. Yang, S. P. Jiang, Adv. Mater. 2018, 30, 1706287; C. Gao, S. Chen, Y. Wang, J. Wang, X. Zheng, J. Zhu, L. Song, W. Zhang, Y. Xiong, Adv. Mater. 2018, 30, 1704624. [6] Z. Geng, Y. Liu, X. Kong, P. Li, K. Li, Z. Liu, J. Du, M. Shu, R. Si, J. Zeng, Adv. Mater. 2018, 30, 1803498. [7] S. Zhou, L. Shang, Y. Zhao, R. Shi, G. I. N. Waterhouse, Y.-C. Huang, L. Zheng, T. Zhang, Adv. Mater. 2019, 31, 1900509.

[8] Y. Xiong, W. Sun, P. Xin, W. Chen, X. Zheng, W. Yan, L. Zheng, J. Dong, J. Zhang, D. Wang, Y. Li, Adv. Mater. 2020, 32, 2000896; Q. Feng, S. Zhao, Q. Xu, W. Chen, S. Tian, Y. Wang, W. Yan, J. Luo, D. Wang, Y. Li, Adv. Mater. 2019, 31, 1901024; A. Bakandritsos, R. G. Kadam, P. Kumar, G. Zoppellaro, M. Medved', J. Tuček, T. Montini, O. Tomanec, P. Andrýsková, B. Drahoš, R. S. Varma, M. Otyepka, M. B. Gawande, P. Fornasiero, R. Zbořil, Adv. Mater. 2019, 31, 1900323.

[9] X. Lu, S. Gao, H. Lin, L. Yu, Y. Han, P. Zhu, W. Bao, H. Yao, Y. Chen, J. Shi, Adv. Mater. 2020, 32, 2002246; H. Xiang, W. Feng, Y. Chen, Adv. Mater. 2020, 32, 1905994.

[10] L. Liu, A. Corma, Chem. Rev. 2018, 118, 4981.

[11] Y. Xue, B. Huang, Y. Yi, Y. Guo, Z. Zuo, Y. Li, Z. Jia, H. Liu, Y. Li, Nat. Commun. 2018, 9, 1460.

[12] M. Liu, L. Wang, K. Zhao, S. Shi, Q. Shao, L. Zhang, X. Sun, Y. Zhao, J. Zhang, Energy \& Environmental Science 2019, 12, 2890.

[13] Z. Pu, I. S. Amiinu, R. Cheng, P. Wang, C. Zhang, S. Mu, W. Zhao, F. Su, G. Zhang, S. Liao, S. Sun, Nano-Micro Letters 2020, 12, 21.

[14] M. Li, H. Wang, W. Luo, P. C. Sherrell, J. Chen, J. Yang, Adv. Mater. 2020, 32, 2001848.

[15] J. Wang, Z. Li, Y. Wu, Y. Li, Adv. Mater. 2018, 30, 1801649.

[16] L. Thöny-Meyer, Microbiology and molecular biology reviews : MMBR 1997, 61, 337. 
[17] K. Richter, M. Schicklberger, J. Gescher, Appl. Environ. Microbiol. 2012, 78, 913; K. D. Bewley, K. E. Ellis, M. A. Firer-Sherwood, S. J. Elliott, Biochimica et Biophysica Acta (BBA) - Bioenergetics 2013, $1827,938$.

[18] S. Kalathil, K. P. Katuri, A. S. Alazmi, S. Pedireddy, N. Kornienko, P. M. F. J. Costa, P. E. Saikaly, Chem. Mater. 2019, 31, 3686.

[19] J. P. Busalmen, A. Esteve-Núñez, A. Berná, J. M. Feliu, Angew. Chem. Int. Ed. 2008, 47, 4874; M. Estevez-Canales, A. Kuzume, Z. Borjas, M. Füeg, D. Lovley, T. Wandlowski, A. Esteve-Núñez, Environmental Microbiology Reports 2015, 7, 219.

[20] K. P. Katuri, N. M. S. Bettahalli, X. Wang, G. Matar, S. Chisca, S. P. Nunes, P. E. Saikaly, Adv. Mater. 2016, 28, 9504.

[21] D. R. Shaw, M. Ali, K. P. Katuri, J. A. Gralnick, J. Reimann, R. Mesman, L. van Niftrik, M. S. M. Jetten, P. E. Saikaly, Nat. Commun. 2020, 11, 2058.

[22] H. Z. Hamdan, D. A. Salam, A. R. Hari, L. Semerjian, P. Saikaly, Sci. Total Environ. 2017, 575, 1453.

[23] N. S. Malvankar, M. Vargas, K. P. Nevin, A. E. Franks, C. Leang, B.-C. Kim, K. Inoue, T. Mester, S. F. Covalla, J. P. Johnson, V. M. Rotello, M. T. Tuominen, D. R. Lovley, Nature Nanotechnology 2011, 6, 573; N. S. Malvankar, D. R. Lovley, ChemSusChem 2012, 5, 1039.

[24] S. Kalathil, K. P. Katuri, P. E. Saikaly, Green Chem. 2020, 22, 5610.

[25] T. Mehta, M. V. Coppi, S. E. Childers, D. R. Lovley, Appl. Environ. Microbiol. 2005, 71, 8634; Y. Yang, M. Xu, J. Guo, G. Sun, Process Biochem. 2012, 47, 1707.

[26] M. F. Alqahtani, K. P. Katuri, S. Bajracharya, Y. Yu, Z. Lai, P. E. Saikaly, Adv. Funct. Mater. 2018, 28, 1804860.

[27] N. Lebedev, R. M. Stroud, M. D. Yates, L. M. Tender, ACS Nano 2019, 13, 4834.

[28] X. Shao, X. Yang, J. Xu, S. Liu, S. Miao, X. Liu, X. Su, H. Duan, Y. Huang, T. Zhang, Chem 2019, 5, 693. [29] J. R. LLOYD, C. LEANG, A. L. H. MYERSON, M. V. COPPI, S. CUIFO, B. METHE, S. J. SANDLER, D. R. LOVLEY, Biochemical Journal 2003, 369, 153; T. S. MAGNUSON, N. ISOYAMA, A. L. HODGES-MYERSON, G. DAVIDSON, M. J. MARONEY, G. G. GEESEY, D. R. LOVLEY, Biochemical Journal 2001, 359, 147; K. Inoue, X. Qian, L. Morgado, B.-C. Kim, T. Mester, M. Izallalen, C. A. Salgueiro, D. R. Lovley, Appl. Environ. Microbiol. 2010, 76, 3999; X. Qian, T. Mester, L. Morgado, T. Arakawa, M. L. Sharma, K. Inoue, C. Joseph, C. A. Salgueiro, M. J. Maroney, D. R. Lovley, Biochimica et Biophysica Acta (BBA) - Bioenergetics 2011, 1807, 404.

[30] C.-C. Chao, M. Motoyama, F. B. Prinz, Adv. Energy Mater. 2012, 2, 651.

[31] P. Li, M. Wang, X. Duan, L. Zheng, X. Cheng, Y. Zhang, Y. Kuang, Y. Li, Q. Ma, Z. Feng, W. Liu, X. Sun, Nat. Commun. 2019, 10, 1711.

[32] K. Jiang, B. Liu, M. Luo, S. Ning, M. Peng, Y. Zhao, Y.-R. Lu, T.-S. Chan, F. M. F. de Groot, Y. Tan, Nat. Commun. 2019, 10, 1743; M. Li, K. Duanmu, C. Wan, T. Cheng, L. Zhang, S. Dai, W. Chen, Z. Zhao, P. Li, H. Fei, Y. Zhu, R. Yu, J. Luo, K. Zang, Z. Lin, M. Ding, J. Huang, H. Sun, J. Guo, X. Pan, W. A. Goddard, P. Sautet, Y. Huang, X. Duan, Nat. Catal. 2019, 2, 495.

[33] L. Cao, Q. Luo, W. Liu, Y. Lin, X. Liu, Y. Cao, W. Zhang, Y. Wu, J. Yang, T. Yao, S. Wei, Nat. Catal. 2019, 2, 134. 


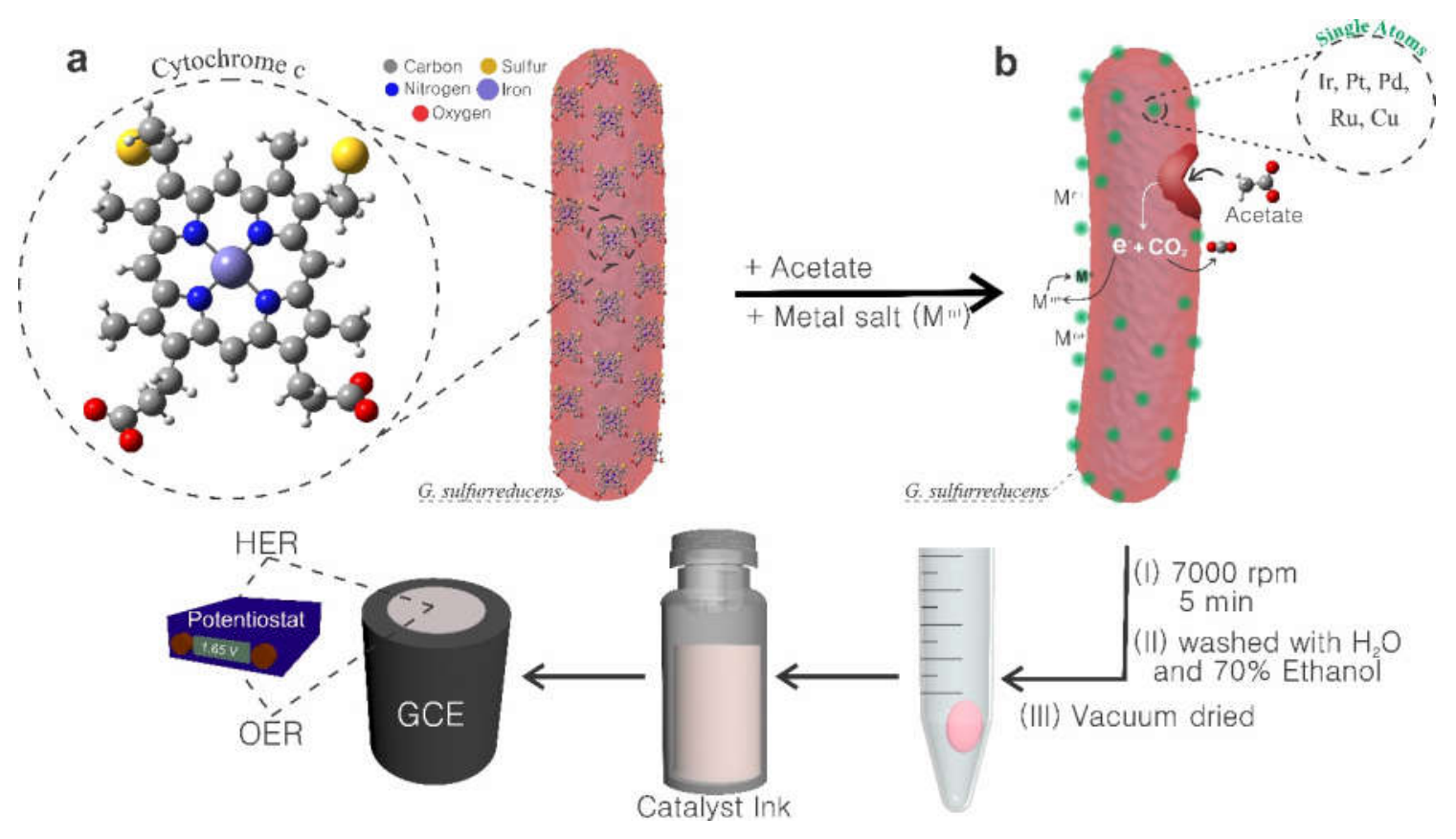

Figure 1. Schematic showing a) G. sulfurreducens cell with expressed heme-containing c-type cytochromes (c-Cyts) on the outer membrane of the cell, which are responsible for the extracellular electron transfer to the acceptor moieties. b) mechanism for the reduction of the metal ions (electron acceptors) on the surface of G. sulfurreducens cell membrane. The metal cations are reduced into individual metal $(\mathrm{M})$ atoms by metabolically generated electrons from the oxidation of acetate (electron donor) inside the cell that are carried by a series of multihemecontaining outer-membrane c-Cyts (OM c-Cyts) to the surface leading to the reduction of metal ions and formation of isolated single-atom metals (SA-Ms) on the surface of G. sulfurreducens cells. $\mathrm{M}=\mathrm{Ir}, \mathrm{Ru}, \mathrm{Pt}, \mathrm{Cu}$ or $\mathrm{Pd}$. 

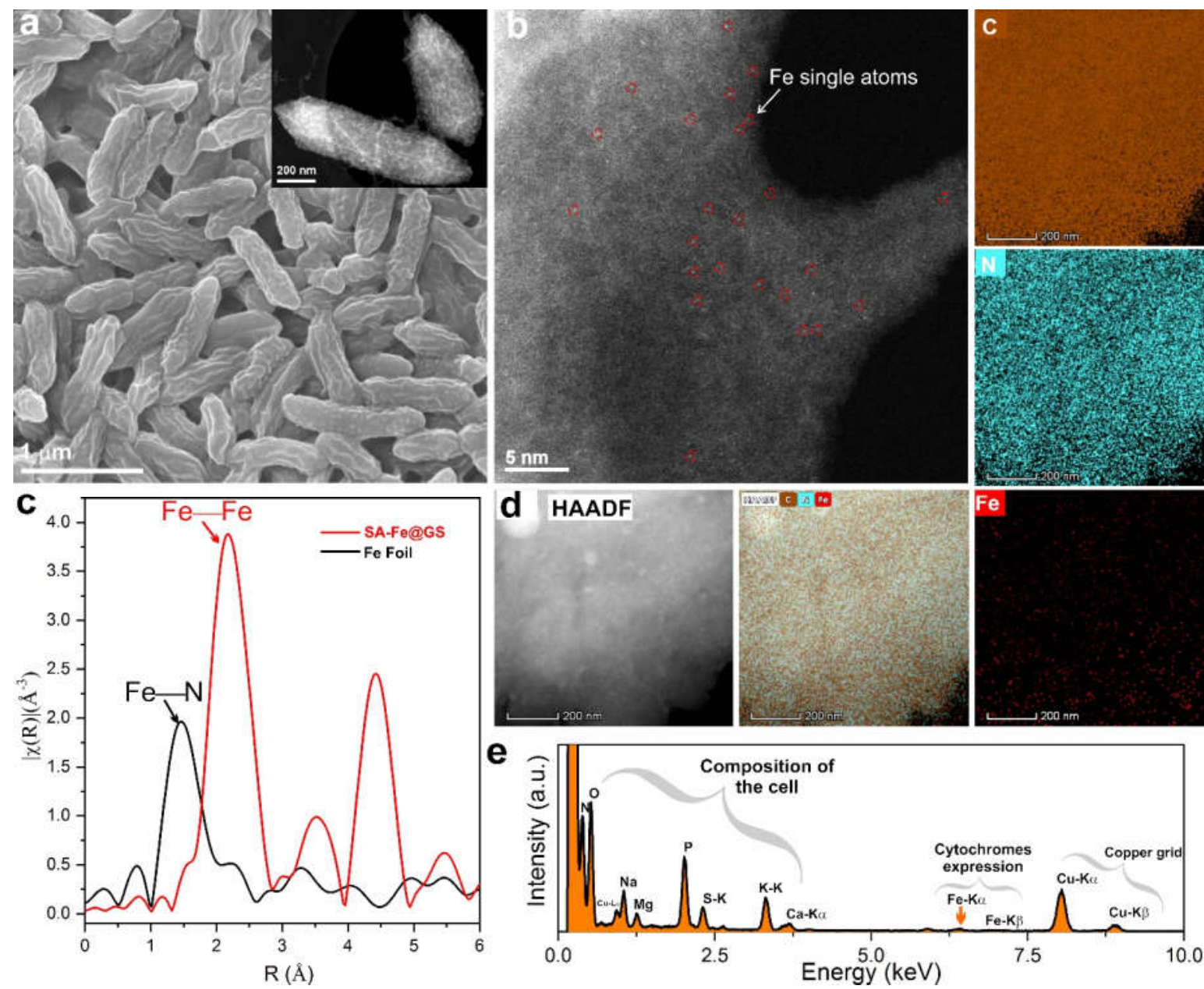

Figure 2. a) Scanning electron microscope (SEM) image, inset showing transmission electron microscopy (TEM) image of SA-Fe@GS. b) High-angle annular dark-field scanning transmission electron microscopy (HAADF-STEM) image of SA-Fe@GS. Individual Fe atoms are emphasized by red circles. c) Fourier transformation spectra of extended X-ray absorption fine structure (FT-EXAFS) at the Fe K-edge of SA-Fe@GS and Fe foil. d) HAADF image and scanning transmission electron microscopy-energy dispersive X-ray spectrometer (STEMEDX) elemental mapping depicting the distribution of $\mathrm{C}$ (orange), $\mathrm{N}$ (cyan), and Fe (red). E) energy dispersive X-ray spectrometer (EDX) spectra showing the elemental composition of the SA-Fe@GS. 

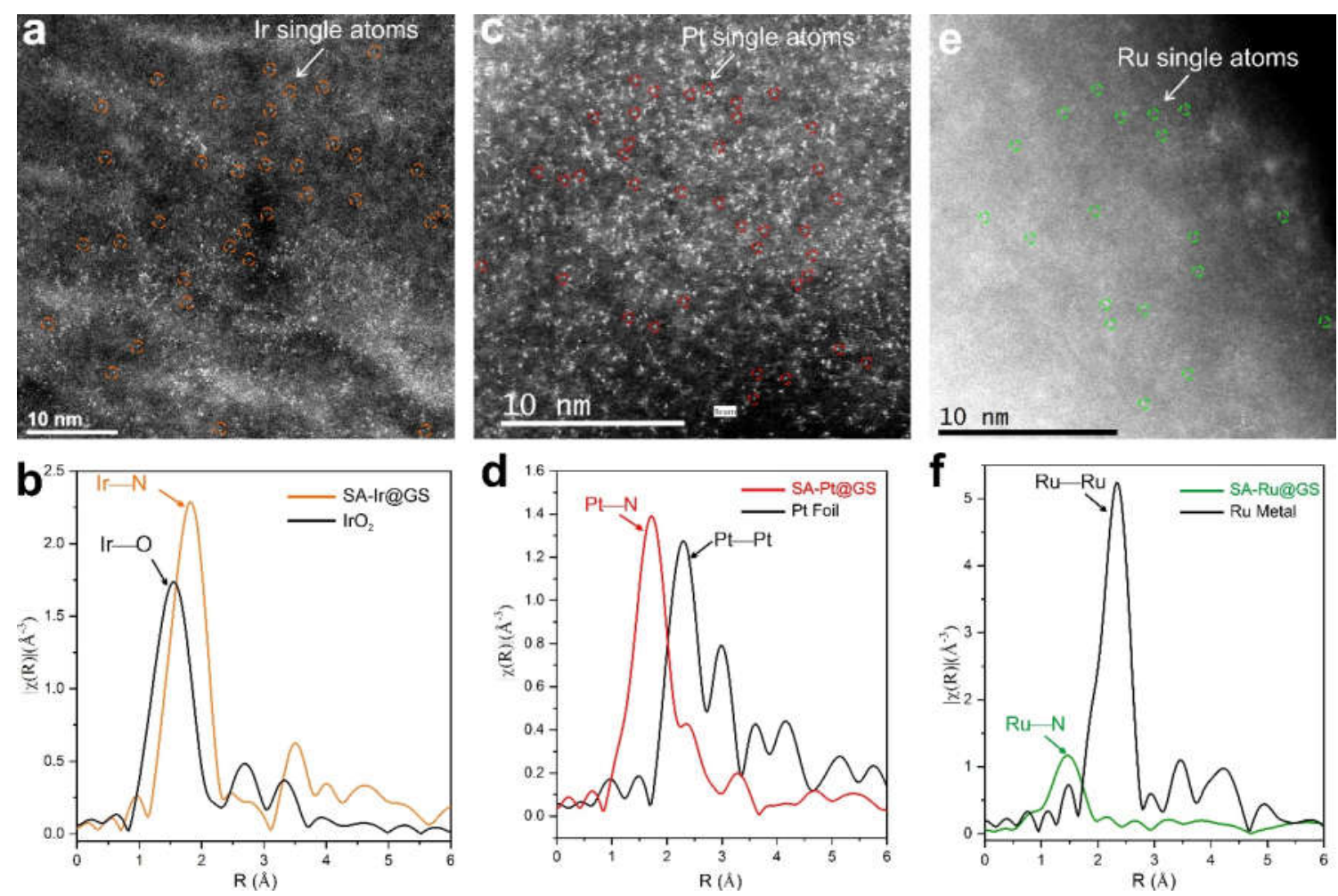

Figure 3. a) High-angle annular dark-field scanning transmission electron microscopy (HAADF-STEM) image of SA-Ir@GS. Single Ir atoms are highlighted by orange circles. b) Fourier transformation spectra of extended X-ray absorption fine structure function (FTEXAFS) at the Ir L 3 -edge of SA-Ir@GS and $\mathrm{IrO}_{2}$. HAADF-STEM images of c) SA-Pt@GS, and e) SA-Ru@GS. Single Pt, and Ru atoms are highlighted by red, and green circles, respectively. FT-EXAFS spectra at the d) Pt $\mathrm{L}_{3}$-edge of SA-Pt@GS and Pt foil, and f) Ru Kedge of SA-Ru@GS and Ru metal. 
a

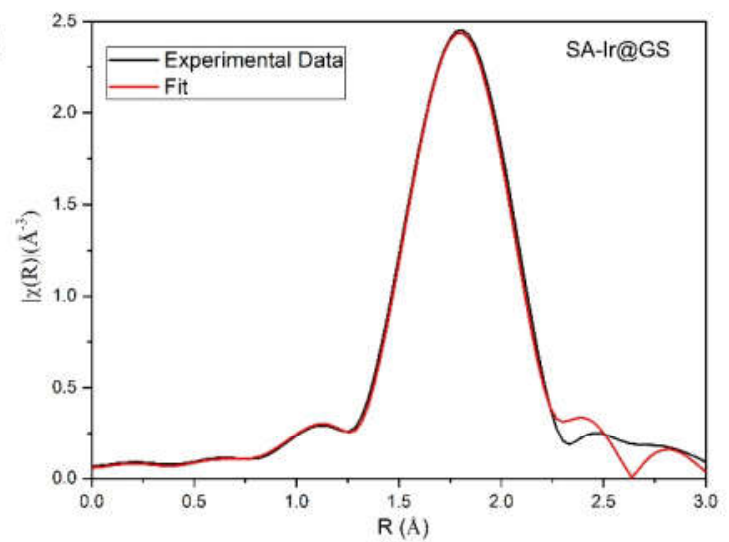

C

\begin{tabular}{|c|c|c|c|}
\hline & $R(\AA)$ & $N$ & $\sigma^{2}\left(\AA^{2}\right)$ \\
\hline Ir-N & $2.11 \pm 0.02$ & $3.0 \pm 0.1$ & $0.0005 \pm 0.0004$ \\
\hline Ir-Fe & $2.31 \pm 0.01$ & $1.0 \pm 0.2$ & $0.0005 \pm 0.0004$ \\
\hline Ir-C & $2.54 \pm 0.02$ & $7.0 \pm 0.1$ & $0.0012 \pm 0.0008$ \\
\hline
\end{tabular}

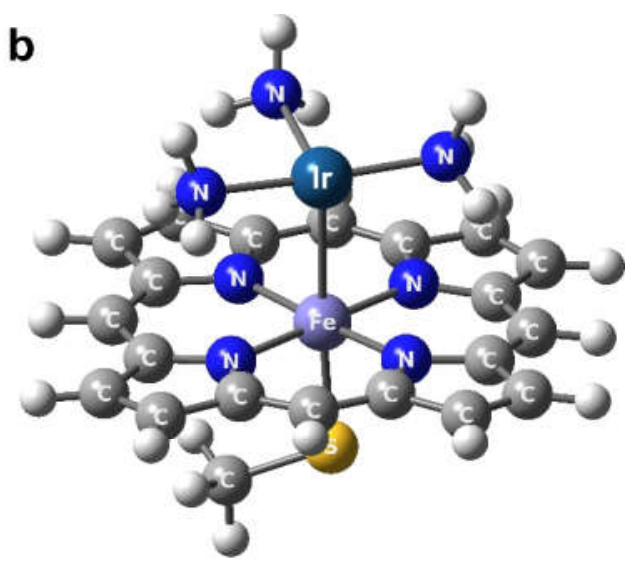

Figure 4. a) Fourier transformed X-ray absorption fine structure (FT-EXAFS) fitting of SAIr@GS catalyst from 1- 2.5 $\AA$ assuming Ir-N, Ir-Fe and Ir-C co-ordination shells. b) density functional theory (DFT)-optimized structure of the SA-Ir@GS catalyst with three nitrogen linkage at the Ir center. Atom colors: C (grey), N (royal blue), Fe (purple blue), Ir (cadet blue), $\mathrm{H}$ (white), S (yellow). c) Table showing the fitted parameters where $\mathrm{R}$ is distance between absorber and backscatter atoms, $\mathrm{N}$ is coordination number, and $\sigma 2$ is Debye-Waller factor. 

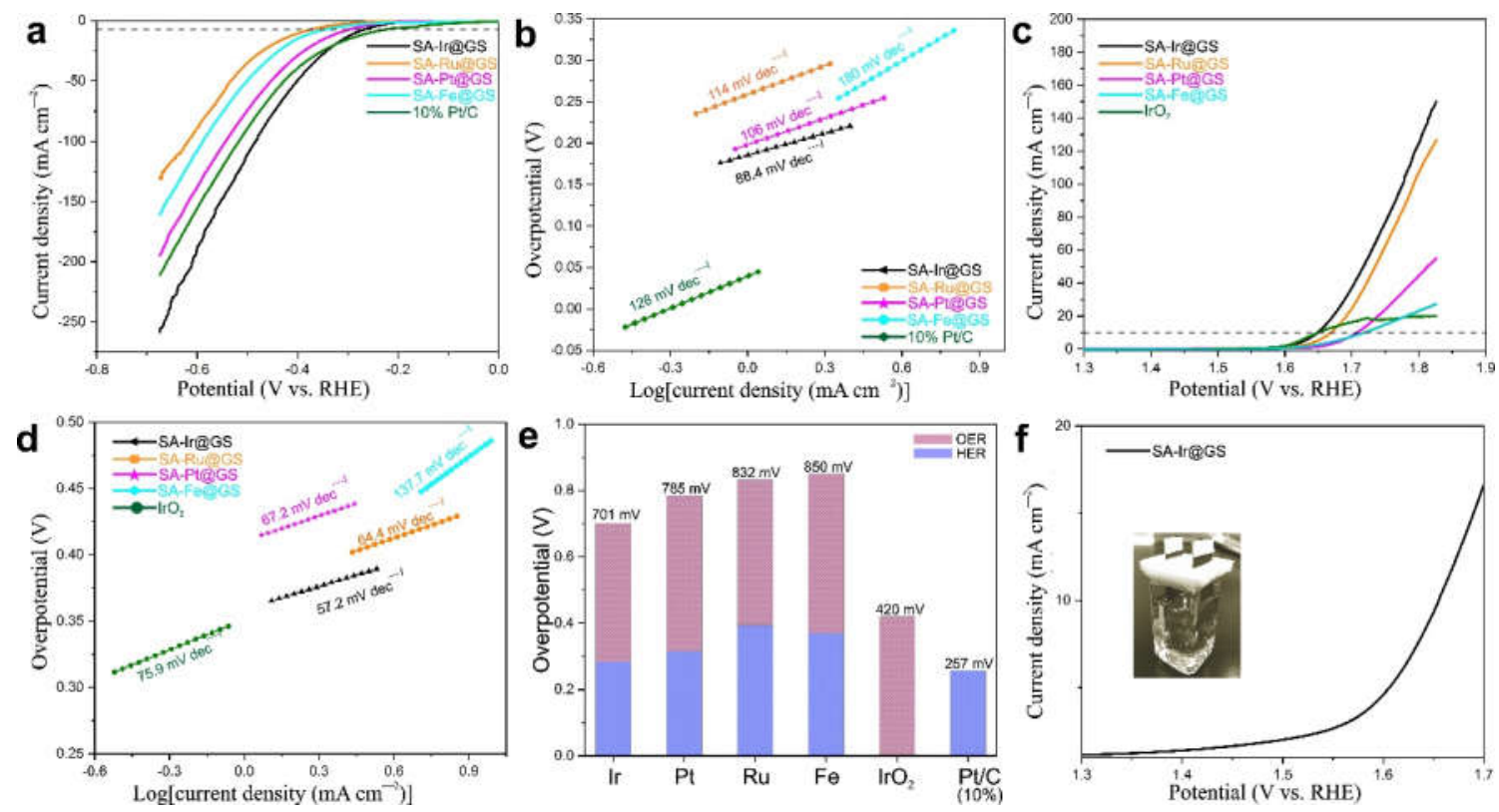

Figure 5. a, c) Linear sweep voltammetry (LSV) of SA-Ir@GS, SA-Ru@GS, SA-Pt@GS, SA$\mathrm{Fe} @ \mathrm{GS}$, commercial 10\% Pt/C and $\mathrm{IrO}_{2}$ electrodes towards hydrogen evolution reaction (HER) and oxygen evolution reaction (OER). b, d) The corresponding Tafel plots obtained from the LSV curves for HER(a) and OER (c), respectively. e) The total overpotential of the appropriate working electrodes obtained at $10 \mathrm{~mA} \mathrm{~cm}^{-2}$. f) The LSV curve of overall water splitting by the SA-Ir@GS electrocatalyst. The HER and OER polarization curves $(j-V)$ were recorded at 5 $\mathrm{mV} \mathrm{s}^{-1}$ at a rotating speed of $1600 \mathrm{rpm}$. 

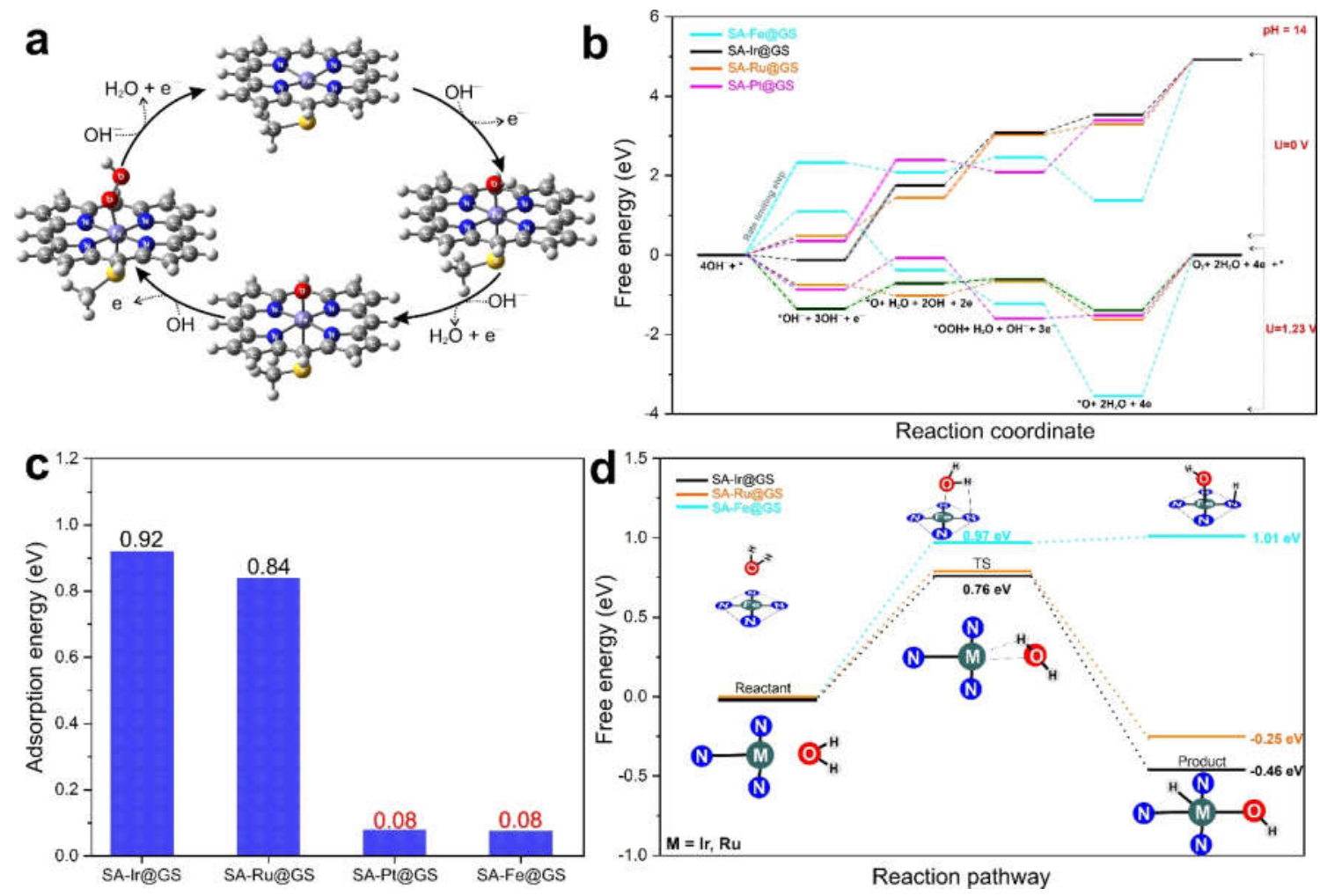

Figure 6. a) Proposed oxygen evolution reaction (OER) mechanism with intermediates using the optimized geometry of the isolated Fe(III)-porphyrin molecule (i.e., SA-Fe@GS). Atom colors: C (grey), N (royal blue), Fe (purple blue), O (red), H (white), S (yellow). b) Free energy diagram for OER over SA-Fe@GS, SA-Ir@GS, SA-Ru@GS, and SA-Pt@GS at potential U = $0 \mathrm{~V}$ and $\mathrm{U}=1.23 \mathrm{~V}$. c) Calculated adsorption energies of $\mathrm{H}_{2} \mathrm{O}$ on the surface of SA-Ir@GS, SA-Ru@GS, SA-Pt@GS and SA-Fe@GS. d) Calculated energy diagram for $\mathrm{H}_{2} \mathrm{O}$ dissociation on SA-Ms for the Volmer step in HER. Atomic models with $\mathrm{H}_{2} \mathrm{O}$ adsorption, transition state (TS) and final step with $\mathrm{OH}$ and $\mathrm{H}$ adsorption demonstrated in the insets. 
Unlocking the Potential of Single Atoms Loaded Geobacter Hybrid Catalyst as Bifunctional Electrocatalyst for Water Splitting

Srikanth Pedireddy*, Mahesh Kumar Ravva, Chandrani Nayak, Dalaver H. Anjum, Shambhu Nath Jha, Krishna P. Katuri, Pascal E. Saikaly*

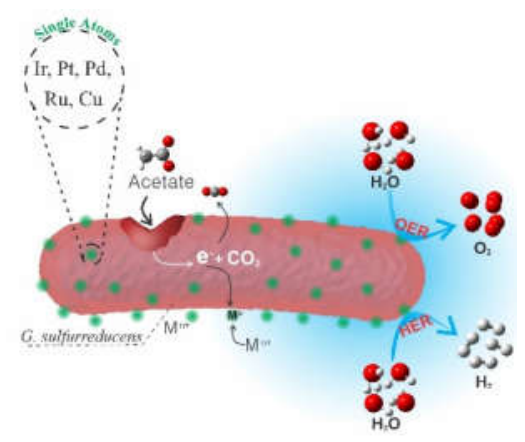




\section{Supporting Information}

\section{Unlocking the Potential of Single Atoms Loaded Geobacter Hybrid Catalyst as Bifunctional Electrocatalyst for Water Splitting}

Srikanth Pedireddy*, Mahesh Kumar Ravva, Chandrani Nayak, Dalaver H. Anjum, Shambhu Nath Jha, Krishna P. Katuri, Pascal E. Saikaly*

\section{Experimental Section}

Bacterial strain and culture conditions: Geobacter sulfurreducens (GS) strain PCA (ATCC 51573 ) was grown in batch cultures. The growth medium solution contained the following salts (per liter): $1.5 \mathrm{~g}$ of $\mathrm{NH}_{4} \mathrm{Cl}, 0.6 \mathrm{~g}$ of $\mathrm{Na}_{2} \mathrm{HPO}_{4}, 0.1 \mathrm{~g}$ of $\mathrm{KCl}, 0.82 \mathrm{~g}$ of sodium acetate, $2.5 \mathrm{~g}$ of $\mathrm{NaHCO}_{3}, 8.0 \mathrm{~g}$ of sodium fumarate, $10 \mathrm{ml}$ of each a vitamin solution and trace element solution. ${ }^{[1]}$ Sodium acetate $(10 \mathrm{mM})$ was provided as the sole carbon and electron source, and fumarate $(50 \mathrm{mM})$ was provided as the electron acceptor. The growth medium was flushed with $\mathrm{N}_{2}-\mathrm{CO}_{2}(80: 20)$ for at least $40 \mathrm{~min}$ to remove oxygen and achieve anaerobic conditions and to maintain the $\mathrm{pH}$ at 7 . Inoculation was performed in an anaerobic glove box, and the culture bottle was kept in an incubator shaker $\left(130 \mathrm{rpm}, 30^{\circ} \mathrm{C}\right)$ for 3 days. Later, the culture suspension was centrifuged at $7000 \mathrm{rpm}$ for $5 \mathrm{~min}$, and the resulting concentrated cell pellet was washed with sterile medium solution (lacking fumarate) three times before being inoculated for the synthesis of single-atom metal (SA-M) catalysts with tunable chemical identity.

Synthesis of single-atom metal (SA-M)catalysts by GS (SA-M@GS): For the synthesis of singleatom platinum $(\mathrm{Pt})$, iridium $(\mathrm{Ir})$, ruthenium $(\mathrm{Ru})$, palladium $(\mathrm{Pd})$, or copper $(\mathrm{Cu})$ on the outer membrane of GS cells, $16 \mathrm{mg}$ of $\mathrm{K}_{2} \mathrm{PtCl}_{6}, 12 \mathrm{mg}$ of $\mathrm{IrCl}_{3} \cdot \mathrm{xH}_{2} \mathrm{O}, 16 \mathrm{mg}$ of $\mathrm{RuCl}_{3} .3 \mathrm{H}_{2} \mathrm{O}, 15 \mathrm{mg}$ of $\mathrm{PdNO}_{3} .2 \mathrm{H}_{2} \mathrm{O}$, or $10 \mathrm{mg}$ of $\mathrm{CuCl}$ was added into $500 \mathrm{~mL}$ of the above anaerobic growth medium solution (without fumarate) in a rubber septated serum vial. Different amounts of the metal precursors were used to maintain a similar metal loading $(3 \mathrm{mg})$ for the different metals. The concentrated cell pellet was inoculated into the serum vials and incubated anaerobically at $30{ }^{\circ} \mathrm{C}$ in the dark for $5 \mathrm{~h}$. The resulting solution was centrifuged at $7000 \mathrm{rpm}$ for 5 minutes, then washed four times with Milli-Q water and 70\% ethanol to remove media components and kill GS cells, and then dried in vacuum dryer at room temperature overnight. The dried samples were used for further characterizations. 
As for SA-Fe@GS, it was prepared by incubating GS with acetate as electron donor and fumarate as electron acceptor. The $\mathrm{Fe}$ is incorporated by GS into the heme group pf cytochromes. The main source of Fe was provided in the media through the trace element solution (as $\mathrm{FeSO}_{4} \times \mathrm{x}_{2} \mathrm{O}$ ). The resulting cell suspension was centrifuged at $7000 \mathrm{rpm}$ for 5 minutes, then washed four times with Milli-Q water and $70 \%$ ethanol to remove media components and then dried in vacuum dryer at room temperature overnight.

Structural and elemental composition characterizations: X-ray diffraction (XRD) patterns for all the samples were collected using a Bruker D8 Advanced A25 diffractometer (Bruker, UK) with $\mathrm{Cu} \mathrm{K}$ radiation, which is operated at $40 \mathrm{kV}$ and $40 \mathrm{~mA}$. The data sets were acquired in the step scan mode in the $2 \theta$ range of $20-80^{\circ}$, using a step interval of $0.05^{\circ}$ and a counting time of $10^{\circ} \min ^{-1}$.

The morphology of all samples was characterized by transmission electron microscopy (TEM), using a Titan 80-300 ST microscope (Thermo-Fisher Scientific, USA) equipped with a probe-corrector to perform the Cs-corrected scanning transmission electron microscopy (STEM) analysis. It was also equipped with an energy dispersive X-ray (EDX) spectrometer and a post-column energy filter for the determination of the elemental composition of samples. The specimens for STEM analysis were prepared by mixing the powdered samples in a pure ethanol solution. A small amount $(<5 \mu \mathrm{L})$ of resultant solution from each sample was then placed on Holey-carbon-coated copper grids. These grids were then air-dried at ambient conditions for several hours before performing the analysis. STEM imaging of the samples was completed by operating the microscope at an accelerating voltage of $300 \mathrm{kV}$, and the images were recorded using a high-angle annular dark-field (HAADF) detector. The scanning electron microscope (SEM) images were taken with a Zeiss Merlin SEM (ZEISS, Germany).

High-resolution X-ray photoelectron spectroscopy (XPS) was used to study the chemical composition and oxidation state of the catalyst surfaces. XPS was carried out using a Kratos Axis Ultra DLD spectrometer (Kratos, UK) equipped with a monochromatic Al Ka X-ray source $(h v=1486.6 \mathrm{eV})$ operating at $150 \mathrm{~W}$, a multichannel plate, and a delay line detector under a vacuum of $1 \times 10^{-9}$ mbar. The survey and high-resolution spectra were recorded at fixed analyzer pass energies of 160 and $20 \mathrm{eV}$, respectively, and quantified using empirically derived relative sensitivity factors provided by Kratos analytical. Samples were mounted in floating mode to avoid differential charging. Charge neutralization was required for all samples. Binding energies were referenced to the $\mathrm{C} 1 \mathrm{~s}$ peak set at $284.8 \mathrm{eV}$. The data were analyzed with CasaXPS software (Casa Software Ltd, UK). 
X-ray Absorption Spectroscopy (XAS) measurements of SA-M@GS samples have been carried out in fluorescence mode using the scanning X-ray absorption fine structure (EXAFS) beamline (BL-09) at the INDUS-2 Synchrotron Source (2.5 GeV, $200 \mathrm{~mA})$ at the Raja Ramanna Centre for Advanced Technology (RRCAT), Indore, India. ${ }^{[2]}$ The beamline uses a double crystal monochromator (DCM), which works in the photon energy range of 4-25 KeV with a resolution of $10^{4}$ at $10 \mathrm{KeV}$. A $1.5 \mathrm{~m}$ horizontal pre-mirror with meridional cylindrical curvature was used prior to the DCM for collimation of the beam and higher harmonic rejection. The second crystal of the DCM is a sagittal cylinder with radius of curvature in the range 1.28-12.91 meters which provides horizontal focusing to the beam while another $\mathrm{Rh} / \mathrm{Pt}$ coated bendable post mirror facing down is used for vertical focusing of the beam at the sample position. For measurements in the fluorescence mode, the sample is placed at $45^{\circ}$ to the incident X-ray beam and the fluorescence signal $\left(I_{f}\right)$ is detected using a Si drift detector placed at $90^{\circ}$ to the incident $\mathrm{X}$-ray beam. An ionization chamber detector is used prior to the sample to measure the incident X-ray flux $\left(I_{0}\right)$ and the absorbance of the sample $\left(\mu=\frac{I_{f}}{I_{0}}\right)$ is obtained as a function of energy by scanning the monochromator over the specified energy range.

The EXAFS spectra were extracted from the absorption spectra as described previously. ${ }^{[3]}$ To take care of the EXAFS oscillations in the absorption spectra, the energy dependent absorption coefficient $\mu(E)$ was converted to absorption function $\chi(E)$ defined as follows:

$$
\chi(E)=\frac{\mu(E)-\mu_{0}(E)}{\Delta \mu_{0}\left(E_{0}\right)}
$$

where $E_{0}$ is absorption edge energy, $\mu_{0}\left(E_{0}\right)$ is the bare atom background and $\Delta_{0}\left(E_{0}\right)$ is the step in the $\mu(E)$ value at the absorption edge. After converting the energy scale to the photoelectron wave number scale $(k)$ as defined by Eq 2, the energy dependent absorption coefficient $\chi(E)$ was converted to the wave number dependent absorption coefficient $\chi(k)$.

$$
k=\sqrt{\frac{2 m\left(E-E_{0}\right)}{\hbar^{2}}}
$$

where $m$ is the electron mass and $\hbar$ is Planck's constant. Finally, $\chi(k)$ is weighted by $k^{2}$ to amplify the oscillation at high $k$ and the functions $\chi(k) k^{2}$ are Fourier transformed (FT) in $r$ space to generate the $\chi(r)$ versus $r$ (or FT-EXAFS) spectra in terms of the real distances from the center of the absorbing atom. The $k$ range used for FT is $2-10 \AA^{-1}$. A set of EXAFS data analysis programs available within the IFEFFIT open source software package was used for 
reduction and fitting of the experimental EXAFS data. ${ }^{[4]}$ This includes data reduction and FT to derive the $\chi(r)$ versus $r$ plots from the absorption spectra, generation of the theoretical EXAFS spectra starting from an assumed crystallographic structure and finally fitting of the experimental $\chi(r)$ versus $r$ data with the theoretical ones using the FEFF 6.0 code.

Electrochemical characterization: The oxygen evolution reaction (OER) and hydrogen evolution reaction (HER) activity of SA-M@GS were tested using a rotating disc electrode (RDE). The working electrode was prepared by the following procedure: the SA-M@GS catalyst ( $2 \mathrm{mg}$ ) was dispersed in $970 \mu \mathrm{l}$ of $50 \%$ ethanol in water mixture and $30 \mu \mathrm{l}$ of Nafion (as a binder). The dispersed solution was sonicated for $1 \mathrm{~h}$, and $2 \mu \mathrm{l}$ of the obtained catalyst ink was drop-coated onto a $3 \mathrm{~mm}$ glassy carbon disc electrode (GCE; loading concentration $\sim 0.049$ $\mathrm{mg} \mathrm{cm}{ }^{-2}$ ) and vacuum dried for $1 \mathrm{~h}$. The electrochemical measurement was carried out using electrochemical working station (BioLogic VMP3, France) in $1 \mathrm{M} \mathrm{KOH}$ (Sigma Aldrich, semiconductor grade, pellets, $99.99 \%$ trace metals basis) at room temperature using a threeelectrodes system, in which Pt mesh and Mercury/Mercury oxide reference electrode $(\mathrm{Hg} / \mathrm{HgO}$; $1 \mathrm{M} \mathrm{KOH})$ were used as counter and reference electrodes, respectively. Linear sweep voltammetry (LSV) experiments were performed at a scan rate of $5 \mathrm{mV} \mathrm{s}^{-1}$ while maintaining a constant rotational speed of $1600 \mathrm{rpm}$ under nitrogen environment.

Density functional theory calculations: All geometry optimizations were carried out using density functional theory (DFT) based B3LYP functional with LANL2DZ basis set for Ru, Fe, Co, Ir, and Pt atoms and 6-31G(d) basis set for $\mathrm{C}, \mathrm{H}, \mathrm{O}, \mathrm{S}$, and $\mathrm{N}$ atoms in the gas phase. The vibrational frequency analysis was carried out on the optimized geometries at the same level of theory to verify that stationary points are real minima and to obtain thermodynamic energy corrections. All calculations were carried out using Gaussian 16 package (Gaussian, Inc., USA). ${ }^{[5]}$

Oxygen evolution reaction: As suggested by previous theoretical and experimental studies, ${ }^{[6]}$ a four-step mechanism is considered for OER as follows:

1. $\mathrm{H}_{2} \mathrm{O}+* \leftrightarrow * \mathrm{OH}+\mathrm{H}^{+}+\mathrm{e}^{-}$

2. ${ }^{*} \mathrm{OH} \leftrightarrow{ }^{*} \mathrm{O}+\mathrm{H}^{+}+\mathrm{e}^{-}$

3. ${ }^{*} \mathrm{O}+\mathrm{H}_{2} \mathrm{O} \leftrightarrow{ }^{*} \mathrm{OOH}+\mathrm{H}^{+}+\mathrm{e}^{-}$

4. $* \mathrm{OOH} \leftrightarrow{ }^{*}+\mathrm{O}_{2}+\mathrm{H}^{+}+\mathrm{e}^{-}$ 
Where * denotes the catalytic active center in Fe-Porphyrin (shown in Figure 6) or M-FePorphyrin model system where $\mathrm{M}=\mathrm{Ir}, \mathrm{Pt}$, and $\mathrm{Ru}$. Several intermediates such as ${ }^{*} \mathrm{OH},{ }^{*} \mathrm{O}$, and * $\mathrm{OOH}$ are observed in the electrocatalysis.

The free energy change for each step was evaluated for the above-mentioned intermediates using the following equations:

$$
\begin{aligned}
& \Delta \mathrm{G}(* \mathrm{OH})=\Delta \mathrm{G}(* \mathrm{OH})+1 / 2 \Delta \mathrm{G}\left(\mathrm{H}_{2}\right)-\Delta \mathrm{G}(*)-\Delta \mathrm{G}\left(\mathrm{H}_{2} \mathrm{O}\right) \\
& \Delta \mathrm{G}(* \mathrm{O})=\Delta \mathrm{G}(* \mathrm{O})+\Delta \mathrm{G}\left(\mathrm{H}_{2}\right)-\Delta \mathrm{G}(*)-\Delta \mathrm{G}\left(\mathrm{H}_{2} \mathrm{O}\right) \\
& \Delta \mathrm{G}(* \mathrm{OOH})=\Delta \mathrm{G}(* \mathrm{OOH})+3 / 2 \Delta \mathrm{G}\left(\mathrm{H}_{2}\right)-\Delta \mathrm{G}(*)-2 \Delta \mathrm{G}\left(\mathrm{H}_{2} \mathrm{O}\right)
\end{aligned}
$$

where, $\Delta \mathrm{G}\left({ }^{*}\right)$ is the free energy of the isolated catalytic complex, and $\Delta \mathrm{G}\left({ }^{*} \mathrm{OH}\right), \Delta \mathrm{G}\left({ }^{*} \mathrm{O}\right)$, and $\Delta \mathrm{G}\left({ }^{*} \mathrm{OOH}\right)$ are the energy of adsorption of the $* \mathrm{O}, * \mathrm{OH}$, and $* \mathrm{OOH}$ on $\mathrm{Fe} / \mathrm{Ir} / \mathrm{Pt} / \mathrm{Co} / \mathrm{Ru}$ catalytic centers, respectively. The $\Delta \mathrm{G}\left(\mathrm{H}_{2}\right)$ and $\Delta \mathrm{G}\left(\mathrm{H}_{2} \mathrm{O}\right)$ are the free energy of $\mathrm{H}_{2} \mathrm{O}$ and $\mathrm{H}_{2}$ molecules in the gas phase.

The free energy diagrams of OER reaction were calculated according to Nørskov et al. ${ }^{[7]}$ computational hydrogen electrode (CHE) model, where the chemical potential of a proton/electron $\left(\mathrm{H}^{+}+\mathrm{e}^{-}\right)$is equal to half of the chemical potential of a gaseous $\mathrm{H}_{2}$.

The free energy change $(\Delta G)$ for each reaction step is given by the following equation:

$$
\Delta \mathrm{G}_{\mathrm{OER}}=\Delta \Delta \mathrm{G}+\Delta \mathrm{G}_{\mathrm{U}}+\Delta \mathrm{G}(\mathrm{pH})
$$

where $\Delta \Delta \mathrm{G}$ is the free energy of reactant and products adsorbed on the catalytic surface. $\Delta \mathrm{G}_{\mathrm{U}}$ is the effect of an external bias which is shifted by $-\mathrm{eU}$. Here, e is the transferred charge and $\mathrm{U}$ is the applied bias. $\Delta \mathrm{G}_{\mathrm{pH}}$ is the $\mathrm{H}^{+}$free energy correction by the concentration dependence of the entropy:

$\Delta \mathrm{G}_{\mathrm{pH}}=-\mathrm{k}_{\mathrm{B}} \mathrm{T} \ln \left[\mathrm{H}^{+}\right]=\mathrm{k}_{\mathrm{B}} \mathrm{T} \ln 10 \times \mathrm{pH}$

where $\mathrm{T}$ and $\mathrm{k}_{\mathrm{B}}$ are temperature and Boltzmann constant, respectively.

According to the Eq 6, the free energy change of the four reaction steps is given by the expression with the adsorption free energies of OER intermediates as follows:

$$
\begin{aligned}
\Delta \mathrm{G}_{1} & =\Delta \mathrm{G} * \mathrm{OH}-\mathrm{eU}+\mathrm{k}_{\mathrm{B}} \mathrm{T} \ln 10 * \mathrm{pH} \\
\Delta \mathrm{G} 2 & =\Delta \mathrm{G} *_{\mathrm{O}}-\Delta \mathrm{G} *_{\mathrm{OH}}-\mathrm{eU}+\mathrm{k}_{\mathrm{B}} \mathrm{T} \ln 10 * \mathrm{pH} \\
\Delta \mathrm{G} 3 & =\Delta \mathrm{G} *_{\mathrm{OOH}}-\Delta \mathrm{G} *_{\mathrm{O}}-\mathrm{eU}+\mathrm{k}_{\mathrm{B}} \mathrm{T} \ln 10 * \mathrm{pH} \\
\Delta \mathrm{G} 4 & =4.92-\Delta \mathrm{G} * *_{\mathrm{OOH}}-\mathrm{eU}+\mathrm{k}_{\mathrm{B}} \mathrm{T} \ln 10 * \mathrm{pH}
\end{aligned}
$$

In the above equations, various conditions such as $\mathrm{pH}=14, \mathrm{~T}=303 \mathrm{~K}$, and $\mathrm{U}=0 \mathrm{~V}$ and 1.23 $\mathrm{V}$ are considered. In the final step, we used the term $4.92 \mathrm{eV}$ which is the free energy of the water splitting process as it is difficult to calculate the accurate energy of $\mathrm{O}_{2}$ molecule using the DFT methods. 
Hydrogen evolution reaction: The thermodynamic reaction energies and energy barrier of water $\mathrm{O}-\mathrm{H}$ bond dissociation were systematically studied to gain insights into HER activity of above-mentioned catalysts. To carry out these reactions, Fe-Porphyrin and M-Fe-Porphyrin $(\mathrm{M}=\mathrm{Ir}, \mathrm{Pt}$, and $\mathrm{Ru})$ were considered. All geometries of reactants, products and transition states were fully optimized using B3LYP method. Furthermore, the transition states corresponding to $\mathrm{O}-\mathrm{H}$ bond dissociation was confirmed by intrinsic reaction coordinates (IRC) analysis at the same level of theory. 
Table S1. Inductively coupled plasma mass spectrometry (ICP-MS) analyses of single atom metal catalysts.

\begin{tabular}{cccccc}
\hline Catalyst & $\begin{array}{c}\text { Weight of } \\
\text { catalyst used } \\
\text { for analysis } \\
{[\mathrm{mg}]}\end{array}$ & $\begin{array}{c}\text { Amount of } \\
\text { metal added } \\
{[\mathrm{mg}]}\end{array}$ & $\begin{array}{c}\text { Amount of } \\
\text { metal in the } \\
\text { catalyst } \\
\text { ICP-MS } \\
{[\mathrm{mg}]}\end{array}$ & $\begin{array}{c}\text { Amount of } \\
\text { residual metal } \\
\text { after reduction } \\
\text { in media } \\
\text { ICP-MS [mg }]\end{array}$ & $\begin{array}{c}\text { Percentage } \\
\text { of metal } \\
\text { reduction } \\
(\%)\end{array}$ \\
\hline SA-Ir@GS & 20 & 3 & 0.178 & 0.34 & 89 \\
SA-Pt@GS & 20 & 3 & 0.182 & 0.27 & 91 \\
SA-Ru@GS & 20 & 3 & 0.196 & 0.06 & 98 \\
SA-Pd@GS & 20 & 3 & 0.2 & 0.005 & 100 \\
SA-Cu@GS & 20 & 3 & 0.198 & 0.02 & 99
\end{tabular}

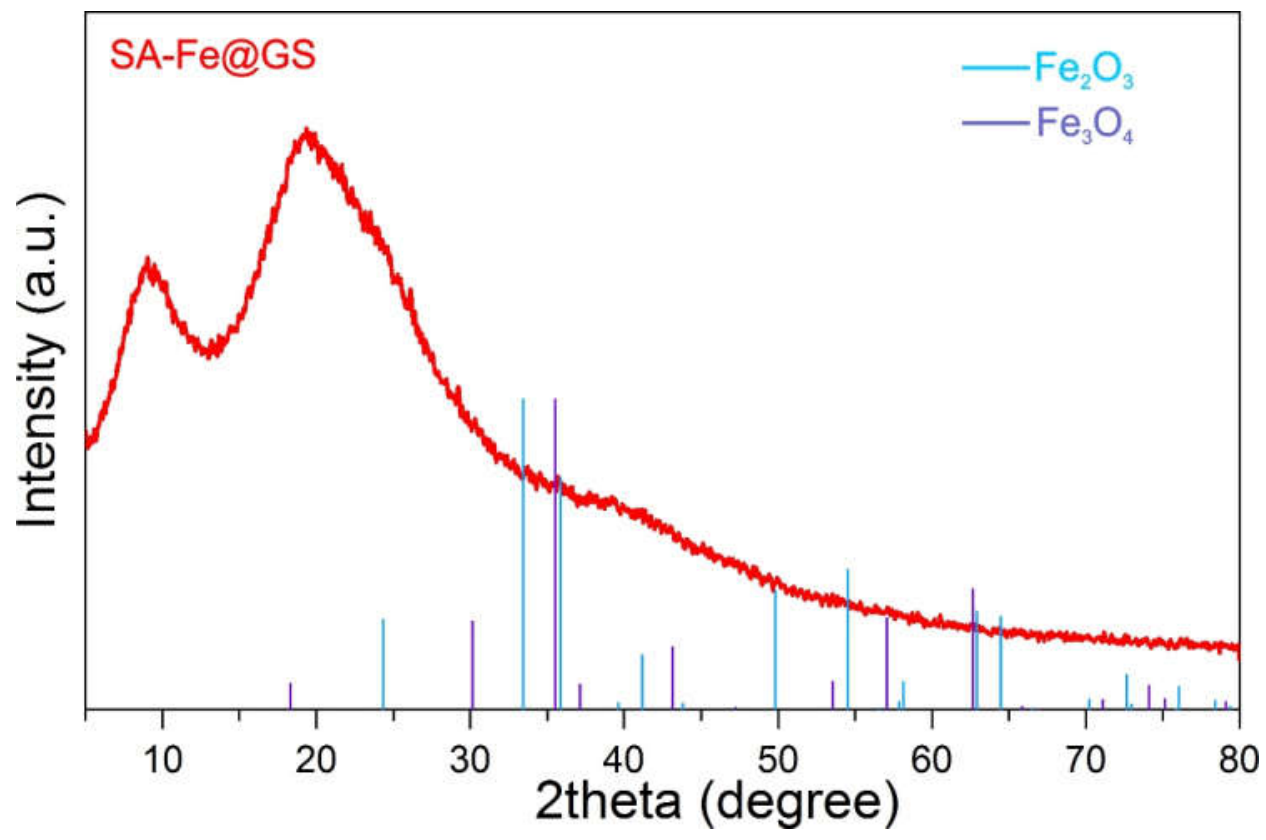

Figure S1. X-ray diffraction (XRD) pattern for SA-Fe@GS derived from G. sulfurreducens. No crystalline peaks of $\mathrm{Fe}$ were observed, further indicating the absence of $\mathrm{Fe}$ clusters/nanoparticles. 

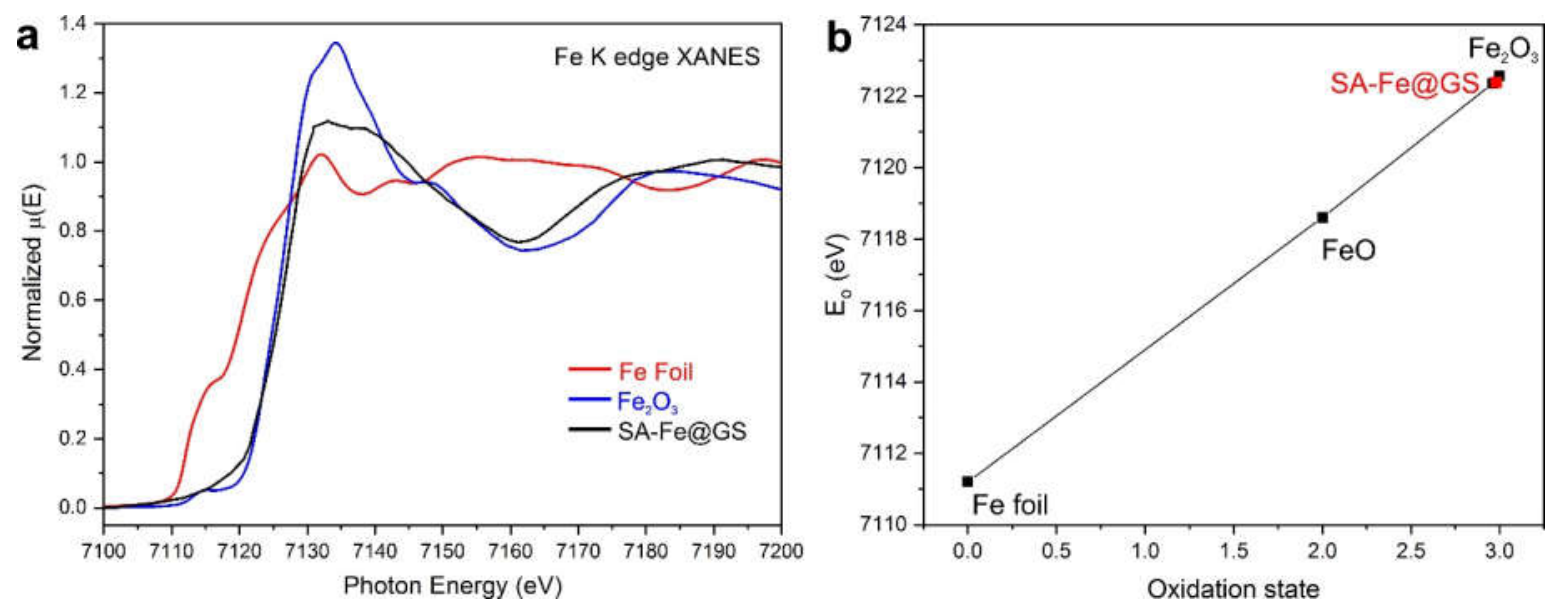

Figure S2. a) X-ray absorption near-edge structure (XANES) of SA-Fe@GS, $\mathrm{Fe}_{2} \mathrm{O}_{3}$, and $\mathrm{Fe}$ foil at Fe K-edge. $\mathrm{b}$ ) The plot of the pre-edge peak position vs. oxidation state of Fe for extended X-ray absorption fine structure (EXAFS) of SA-Fe@GS, $\mathrm{Fe}_{2} \mathrm{O}_{3}$, and Fe foil at Fe K-edge.
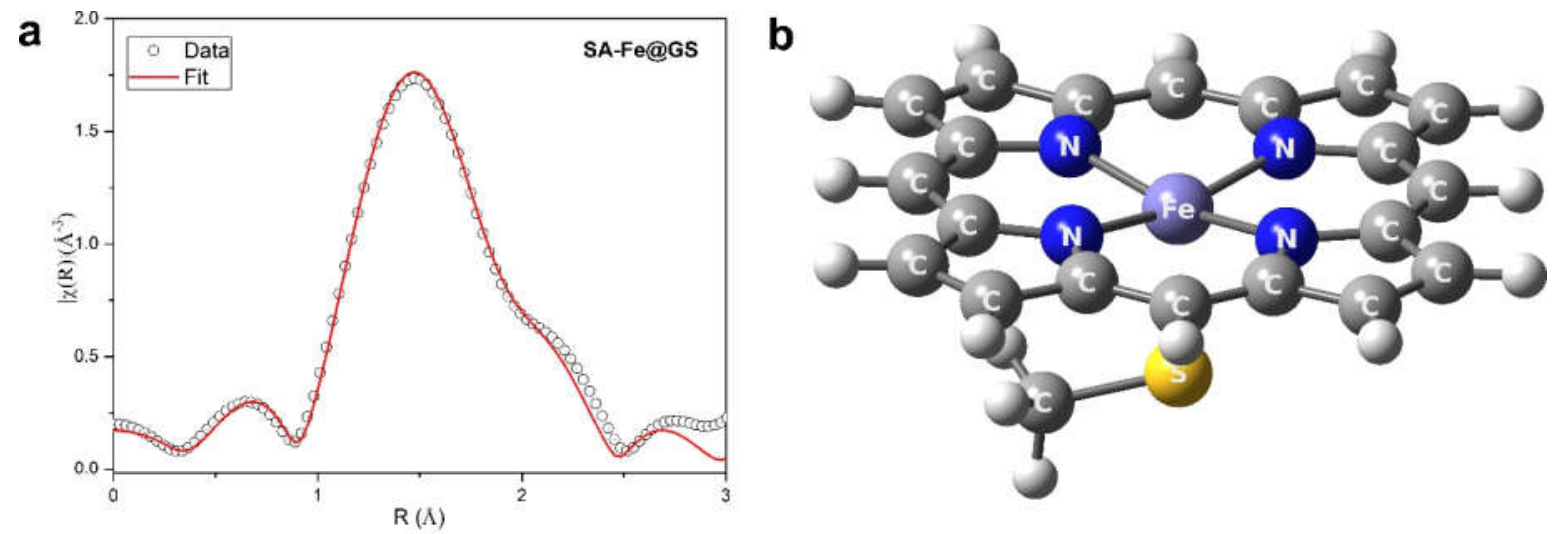

C
\begin{tabular}{|c|c|c|c|}
\hline & $R(\AA)$ & $N$ & $o^{2}\left(\AA^{2}\right)$ \\
\hline Fe-N & $2.01 \pm 0.03$ & $4.2 \pm 0.4$ & $0.001 \pm 0.0007$ \\
\hline Fe-S & $2.21 \pm 0.03$ & $1.1 \pm 0.3$ & $0.001 \pm 0.0006$ \\
\hline Fe-C & $2.45 \pm 0.05$ & $3.2 \pm 0.6$ & $0.001 \pm 0.0008$ \\
\hline
\end{tabular}

Figure S3. a) Fourier transformed X-ray absorption fine structure (FT-EXAFS) fitting of SAFe@GS catalyst from 1-2.5 $\AA$ assuming Fe-N, Fe-S and Fe-C co-ordination shells. b) density functional theory (DFT)-optimized structure of the SA-Fe@GS catalyst. Atom colors: C (grey), $\mathrm{N}$ (royal blue), Fe (purple blue), $\mathrm{H}$ (white), $\mathrm{S}$ (yellow). c) Table showing the fitted parameters where $\mathrm{R}$ is the distance between absorber and backscatter atoms, $\mathrm{N}$ is coordination number, and $\sigma 2$ is Debye-Waller factor. 


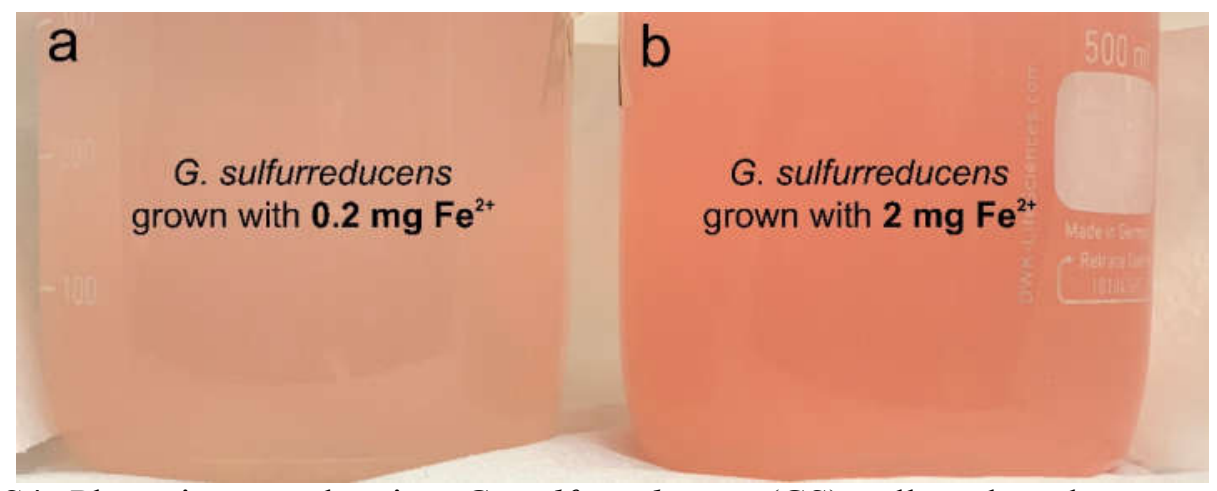

Figure S4. Photo images showing G. sulfurreducens (GS) cells cultured at two different concentrations of $\mathrm{Fe}^{2+}$ in the growth media a) $0.2 \mathrm{mg} \mathrm{Fe}{ }^{2+}$ and b) $2 \mathrm{mg} \mathrm{Fe}^{2+}$.
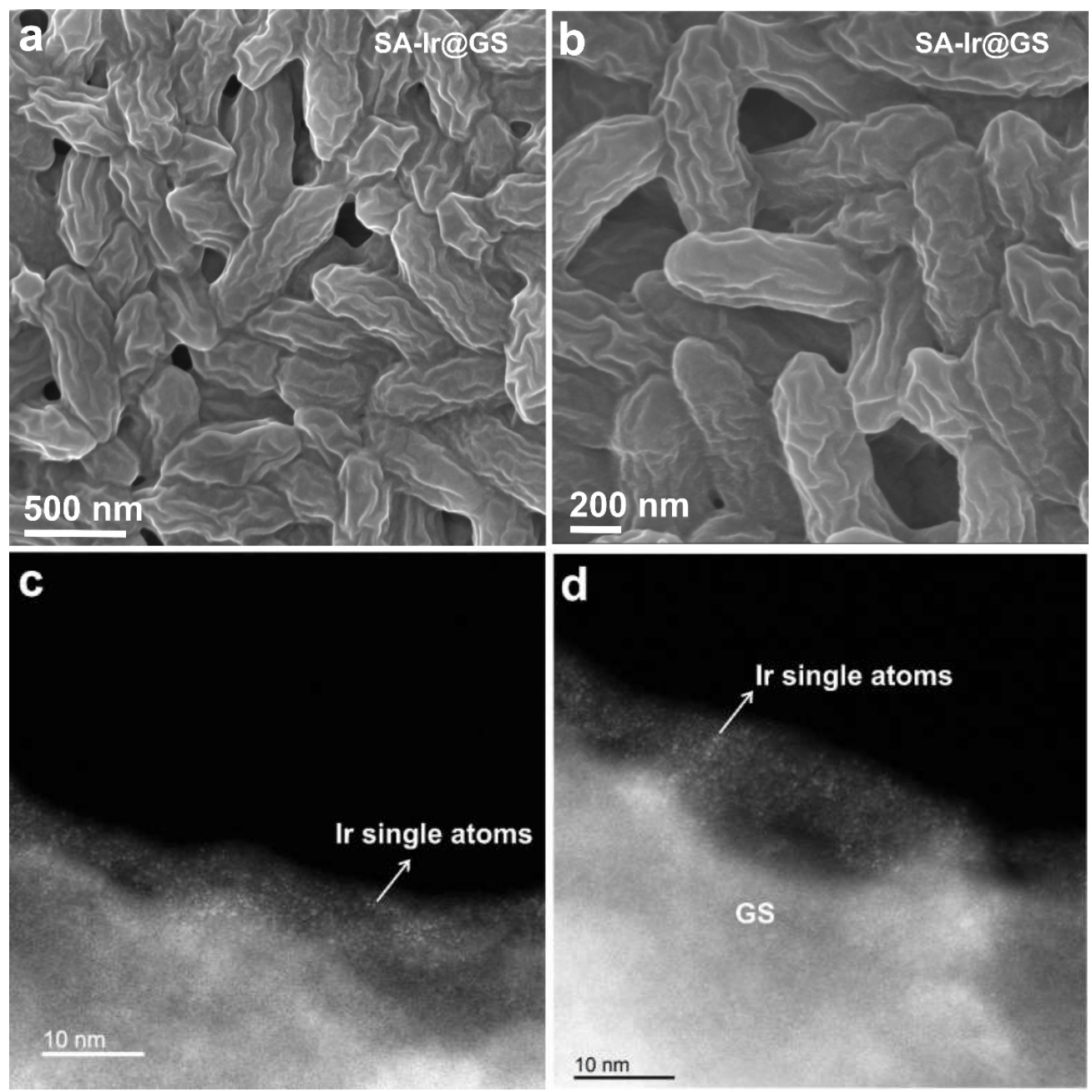

Figure S5. a-b) High magnification scanning electron microscope (SEM) images showing the crumpled morphology of the SA-Ir@GS cells, indicating the absence of nanoparticle formation. c-d) High-angle annular dark-field scanning transmission electron microscopy (HAADFSTEM) images of SA-Ir@GS, indicating the presence of atomically dispersed Ir on the surface of $G$. sulfurreducens (GS) dead cells. 

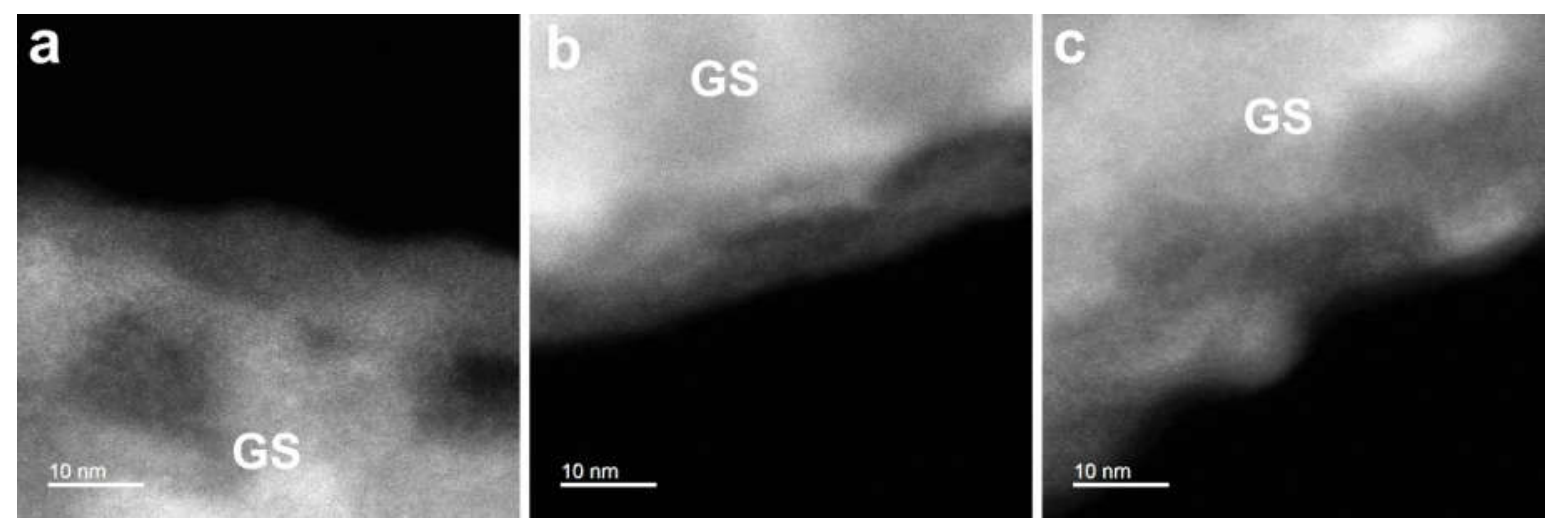

Figure S6. a-c) High-angle annular dark-field scanning transmission electron microscopy (HAADF-STEM) images of G. sulfurreducens (GS) dead cells fed with $\mathrm{Ir}^{3+}$ (electron acceptor) in the absence of acetate (electron donor). Adsorption or formation of Ir atoms on surface of cell was not observed like in Figure S4.
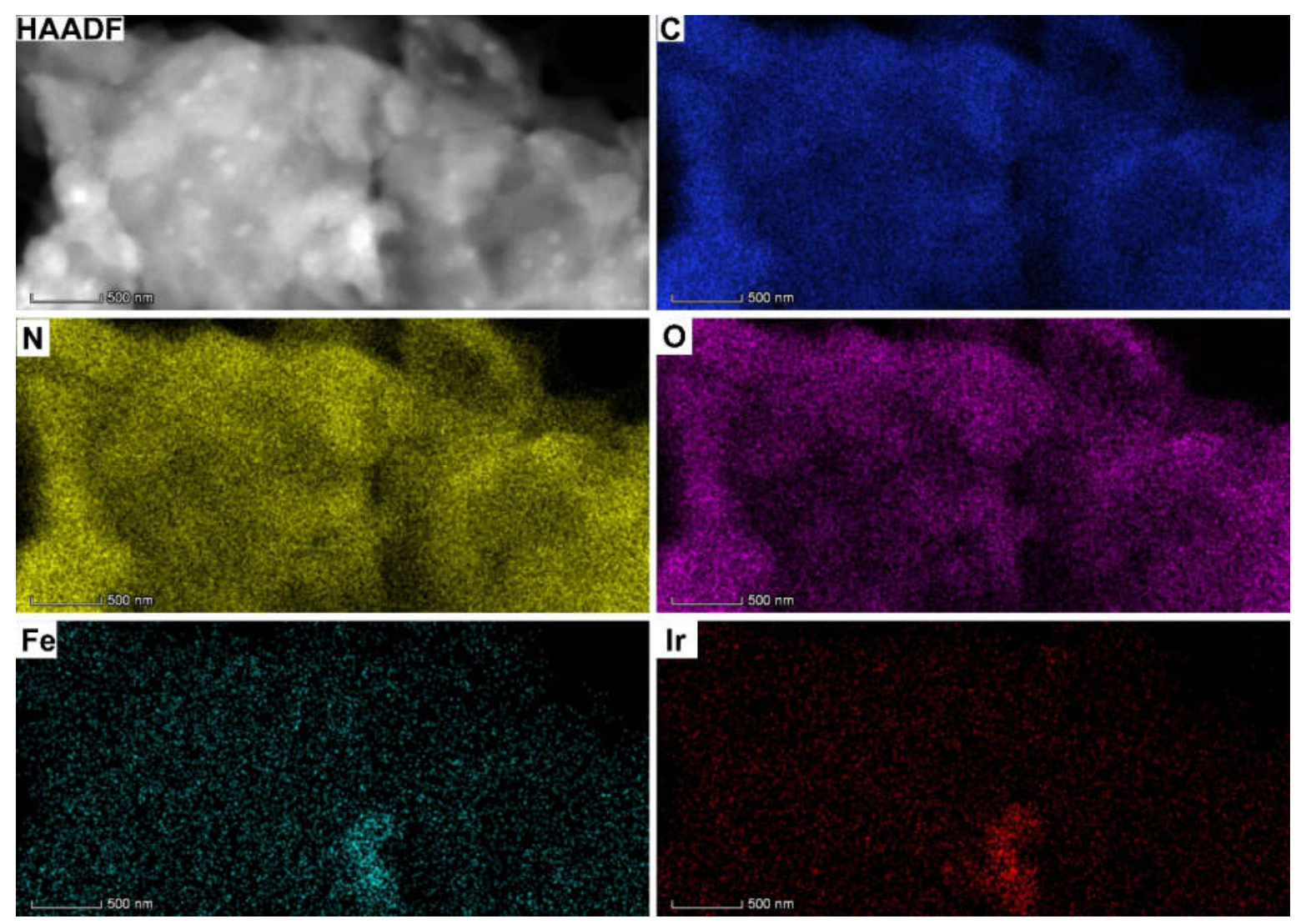

Figure S7. High-angle annular dark-field (HAADF) image and scanning transmission electron microscopy-energy dispersive X-ray spectrometer (STEM-EDX) elemental mapping of SAIr@GS. EDX mapping indicating that Ir is present at Fe site, confirming the role of Fecontaining (heme) cytochromes in the reduction of Ir ions to metallic Ir. 

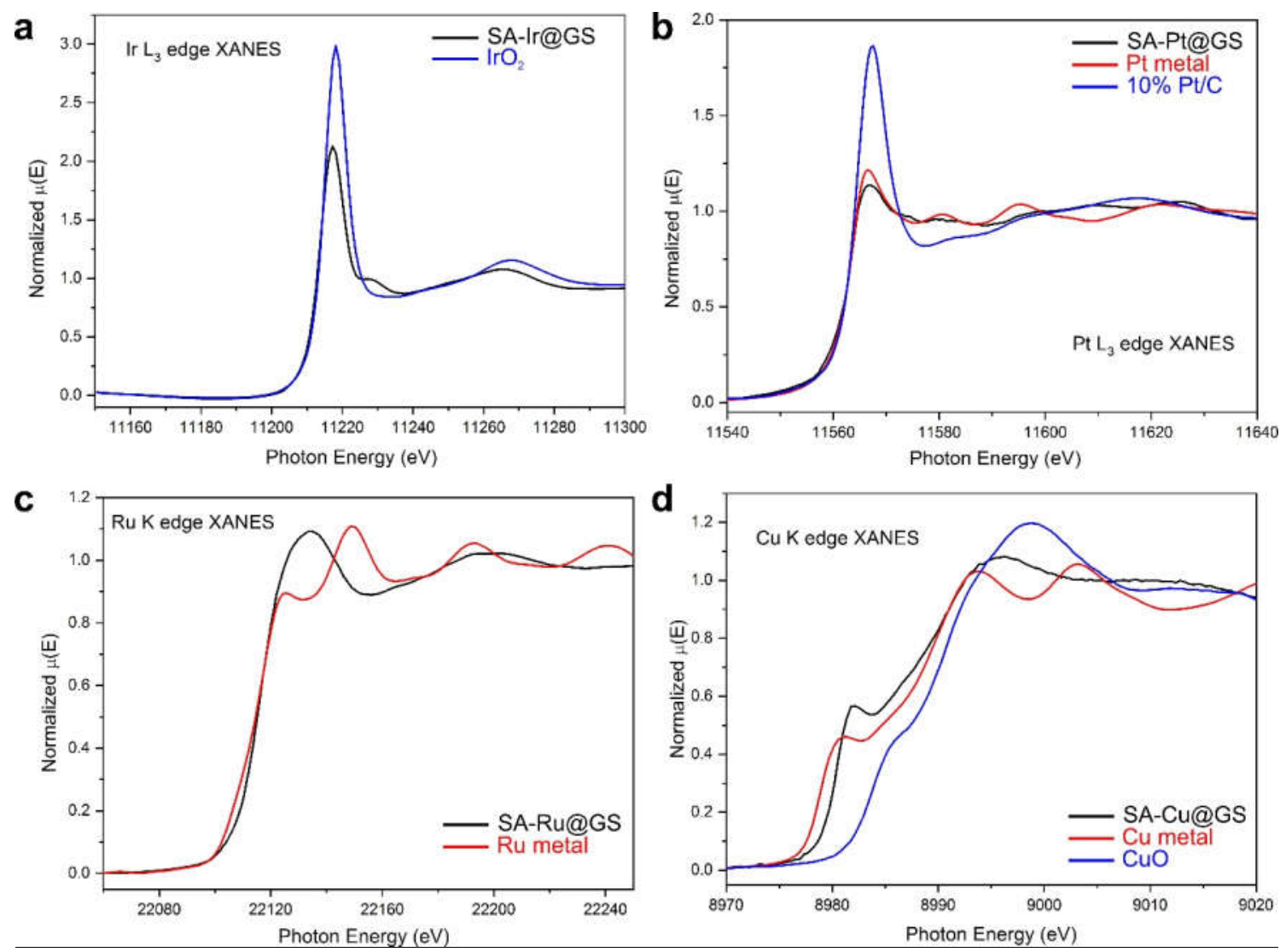

Figure S8. X-ray absorption near-edge structure (XANES) spectra of a) SA-Ir@GS, b) SAPt@GS, c) SA-Ru@GS, and d) SA-Cu@GS with their corresponding reference materials. 

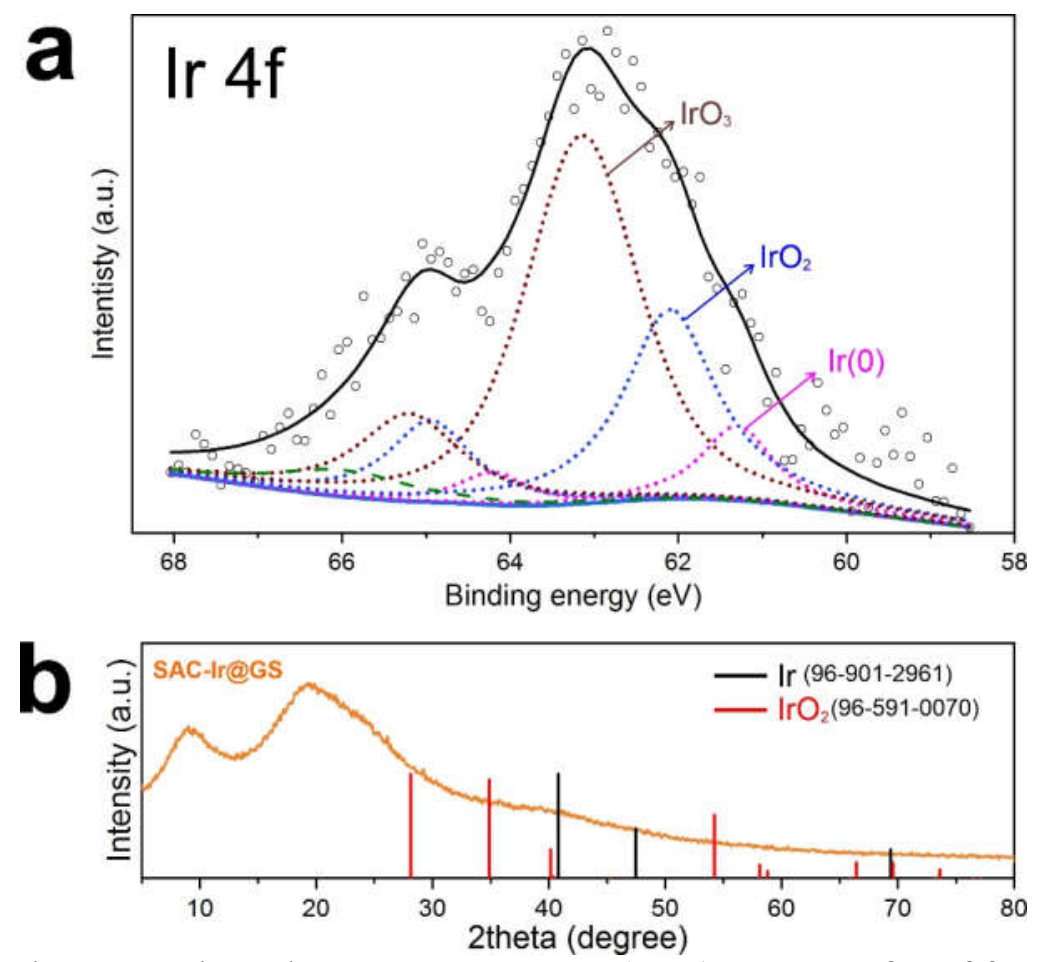

Figure S9. a) The X-ray photoelectron spectroscopy (XPS) patterns of Ir 4f for SA-Ir@GS. b) X-ray diffraction (XRD) pattern for SA-Ir@GS.

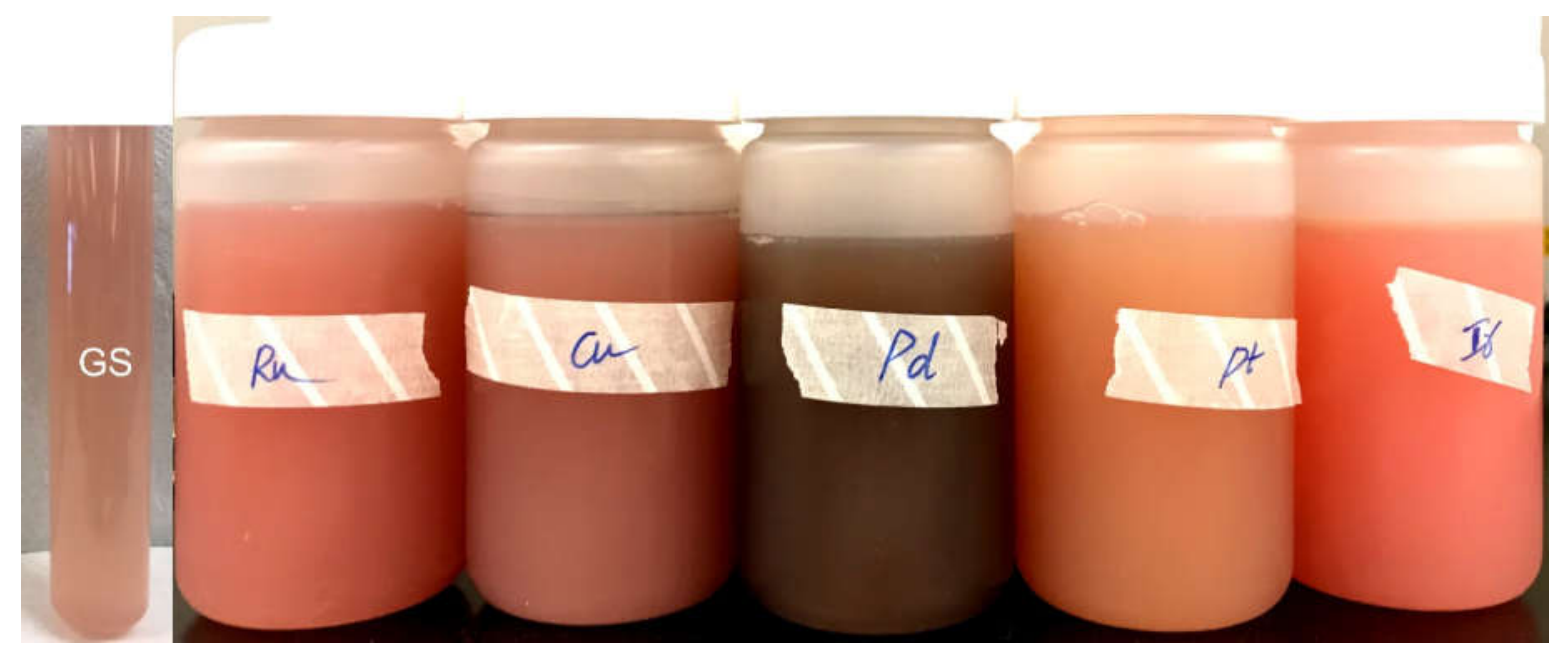

Figure S10. Photo images showing the change in solution color after the reduction of metal cations by $G$. sulfurreducens. 

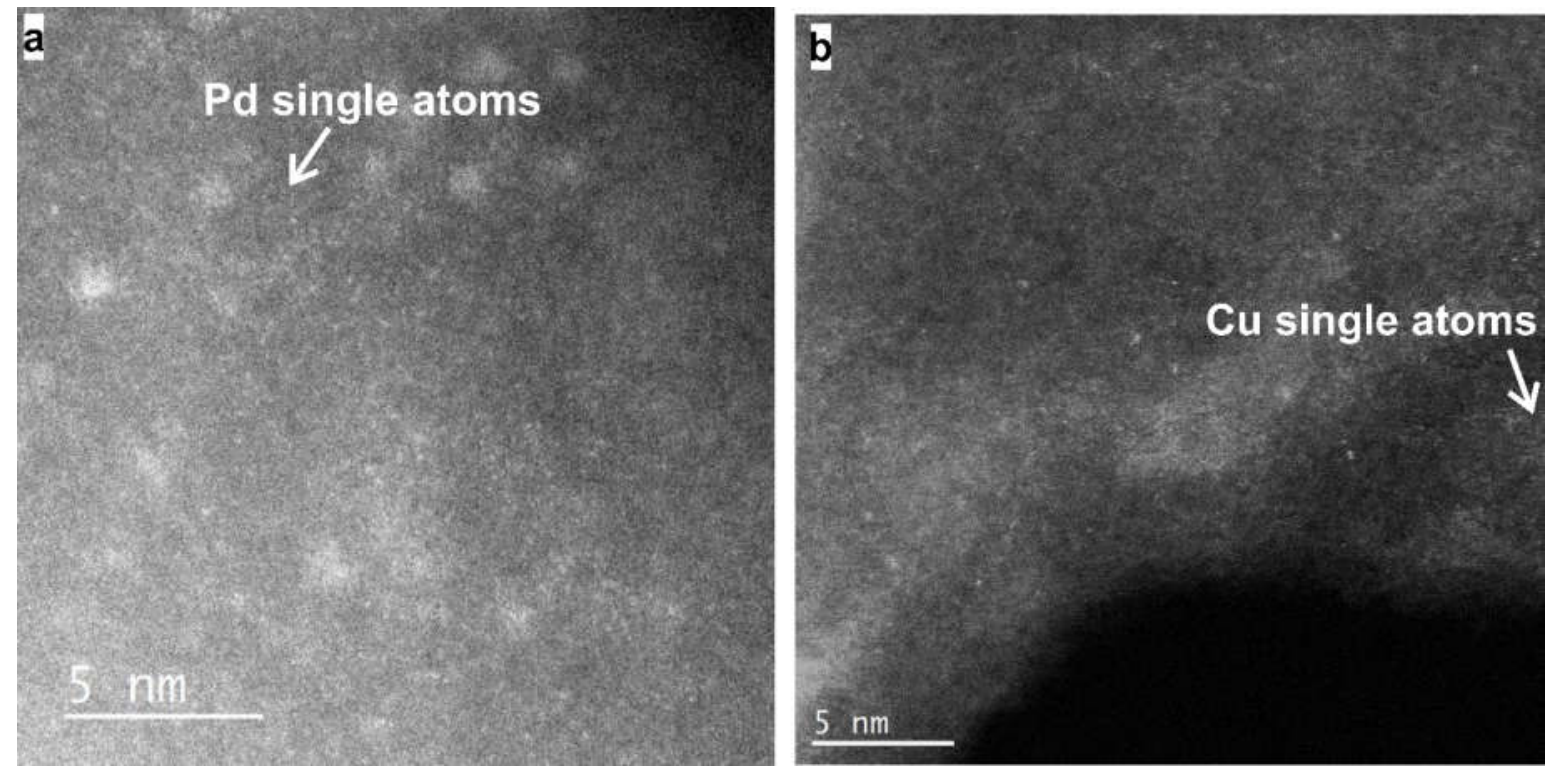

Figure S11. Scanning transmission electron microscopy (STEM) images of a) SA-Pd@GS and b) SA-Cu@GS confirming the atomic dispersion of single atoms. 

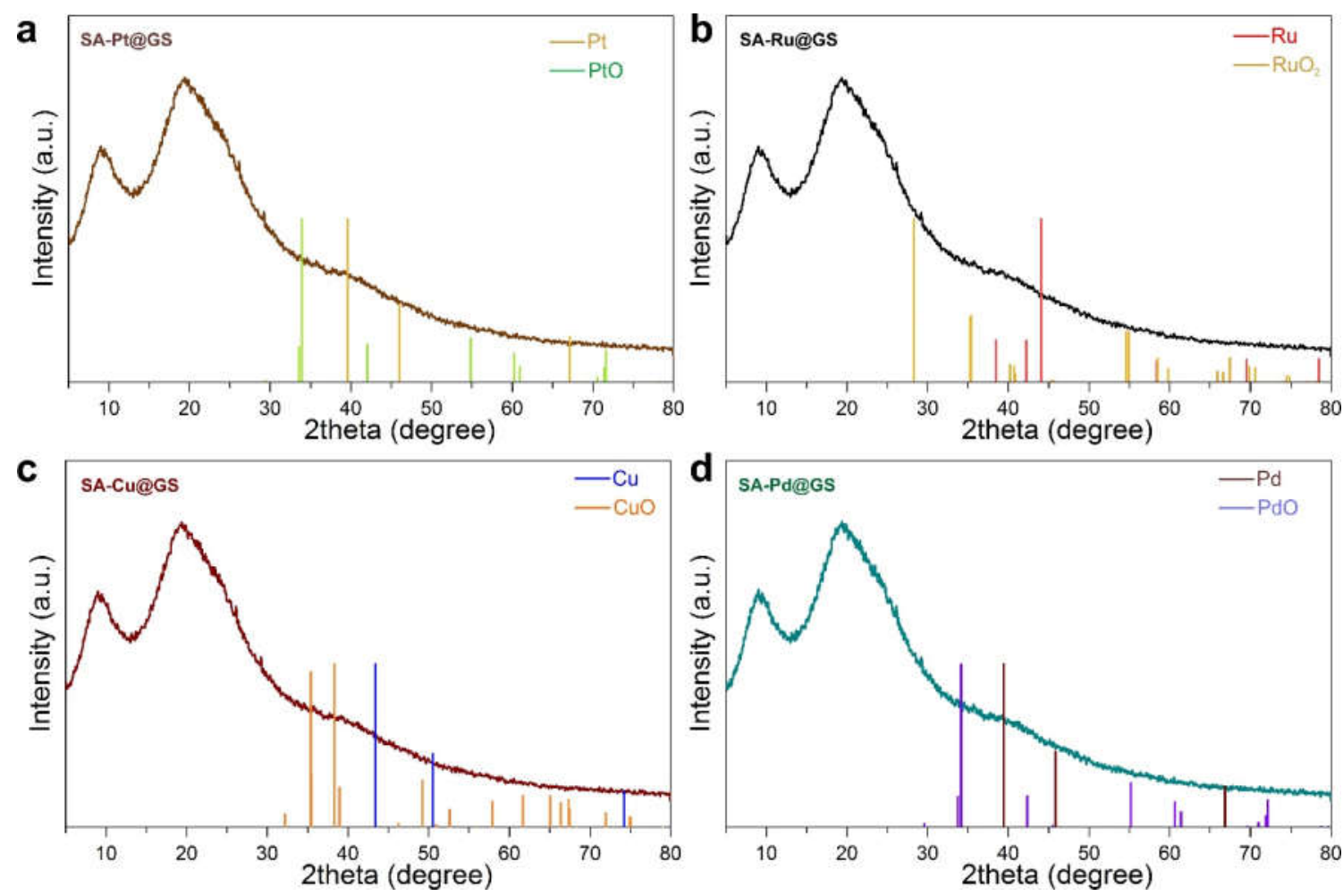

Figure S12. X-ray diffraction (XRD) spectra of a) SA-Pt@GS, b) SA-Ru@GS, c) SA-Cu@GS, and d) SA-Pd@GS, indicating the absence of crystalline peaks corresponding to clusters/nanoparticles of the respective metals. 

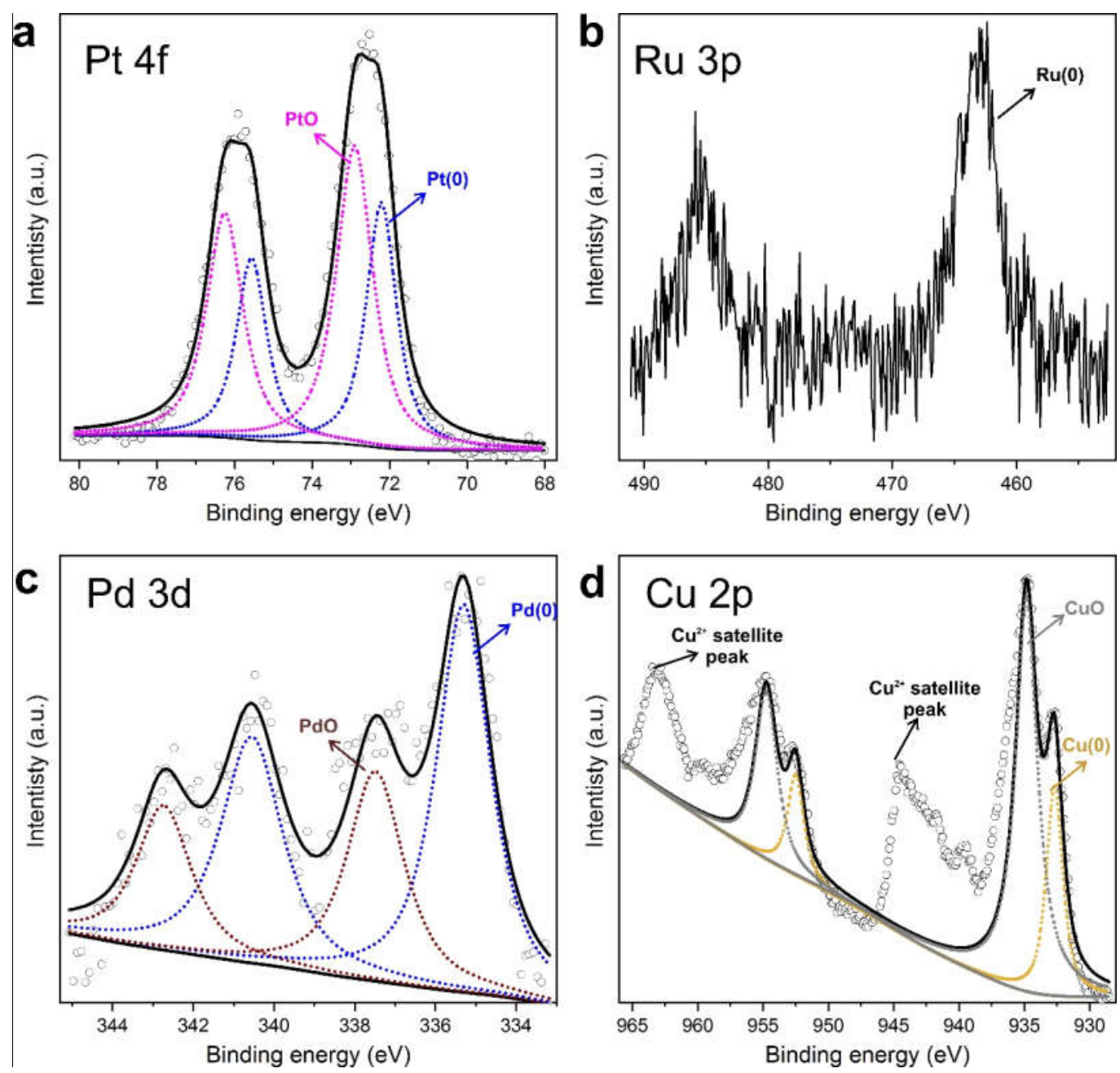

Figure S13. High resolution X-ray photoelectron spectroscopy (XPS) spectra of a) Pt in SAPt@GS, b) Ru in SA-Ru@GS, c) Pd in SA-Pd@GS, and d)Cu in SA-Cu@GS, showing the metallic states of the respective elements along with their oxide forms. 
a
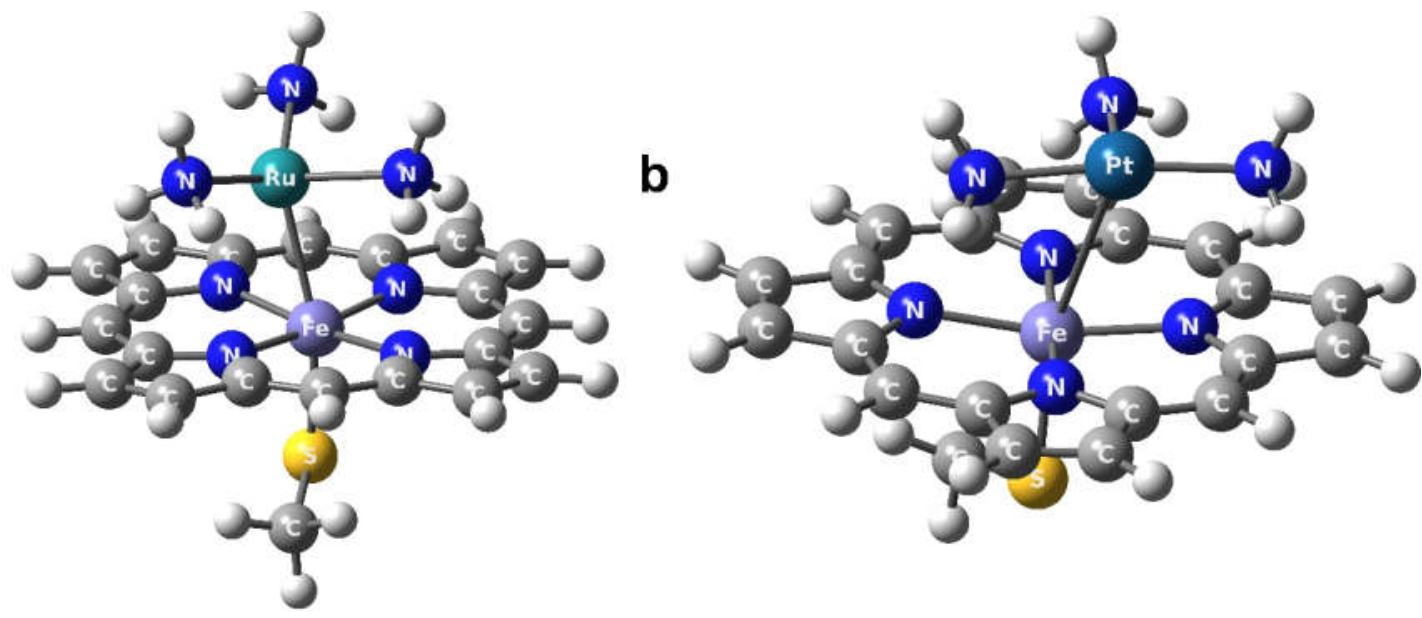

Figure S14. Optimized geometries of a) SA-Ru@GS, and b) SA-Pt@GS,complexes as determined using B3LYP functional with LANL2DZ basis set for $\mathrm{Ru}$, and Pt atoms and 6$31 \mathrm{G}(\mathrm{d})$ basis set for $\mathrm{C}, \mathrm{H}, \mathrm{O}, \mathrm{S}$, and $\mathrm{N}$ atoms. Atom colors other than the metals: C (grey), N (royal blue), $\mathrm{H}$ (white), and $\mathrm{S}$ (yellow). 
Table S2. Summary of single-atom electrocatalysts for the HER.

\begin{tabular}{|c|c|c|c|c|c|c|c|}
\hline Catalysts & $\begin{array}{c}\text { Metal } \\
\text { configurati } \\
\text { on } \\
\end{array}$ & $\begin{array}{c}\text { Metal } \\
\text { content } \\
{[\mathrm{wt} . \%]}\end{array}$ & $\begin{array}{l}\text { Loading } \\
{\left[\mathrm{mg} \mathrm{cm}^{-2}\right]}\end{array}$ & Electrolytes & $\begin{array}{c}\eta \\
{[\mathrm{mV}]}\end{array}$ & $\begin{array}{l}\text { Tafel slope } \\
{\left[\mathrm{mV} \mathrm{dec}^{-1}\right]}\end{array}$ & Reference \\
\hline SA-Ir@GS & Ir-N 3 & 0.89 & 0.004 & $1 \mathrm{M} \mathrm{KOH}$ & 283 & 88.4 & This work \\
\hline $\mathrm{Pt} / \mathrm{C}$ & $\mathrm{Pt}$ & 10 & 0.004 & $1 \mathrm{M} \mathrm{KOH}$ & 257 & 128 & This work \\
\hline Co-NG & $\mathrm{Co}-\mathrm{N}_{x}$ & $\begin{array}{l}0.57 \\
\text { at. } \%\end{array}$ & 0.285 & $1 \mathrm{M} \mathrm{NaOH}$ & 270 & - & [8] \\
\hline $\begin{array}{c}\text { Co- } \\
\text { substituted } \\
\mathrm{Ru}\end{array}$ & Co- $\mathrm{Ru}_{x}$ & 6 at. $\%$ & 0.153 & $1 \mathrm{M} \mathrm{KOH}$ & 13 & 29 & [9] \\
\hline $\mathrm{Co}_{1} / \mathrm{PCN}$ & $\mathrm{Co}_{1}-\mathrm{N}_{4}$ & 0.3 & 0.5 & $1 \mathrm{M} \mathrm{KOH}$ & 89 & 52 & {$[10]$} \\
\hline $\begin{array}{c}\mathrm{Fe}-\mathrm{N}_{4} \\
\mathrm{SAs} / \mathrm{NPC}\end{array}$ & $\mathrm{Fe}-\mathrm{N}_{4}$ & 1.96 & 2 & $1 \mathrm{M} \mathrm{KOH}$ & 202 & 123 & [11] \\
\hline $\begin{array}{c}\operatorname{Ir}_{1} @ \mathrm{Co} / \mathrm{N} \\
\mathrm{C}\end{array}$ & $\mathrm{IrNC}_{3}$ & 2.2 & 0.2 & $1 \mathrm{M} \mathrm{KOH}$ & 60 & 119 & [12] \\
\hline $\mathrm{Pt}$ SAs/DG & $\mathrm{Pt}-\mathrm{C}_{4}$ & 2.1 & 1 & $1 \mathrm{M} \mathrm{KOH}$ & 35 & - & [13] \\
\hline $\begin{array}{c}\mathrm{Pt} / \mathrm{np}- \\
\mathrm{Co}_{0.85} \mathrm{Se}\end{array}$ & $\mathrm{Pt}^{-\mathrm{Se}_{x}}$ & 1.03 & 2.04 & $1 \mathrm{M} \mathrm{KOH}$ & 58 & 39 & [14] \\
\hline $\mathrm{Pt} @ \mathrm{PCM}$ & Pt-N 4 & 0.53 & - & $1 \mathrm{M} \mathrm{KOH}$ & 139 & 73.6 & [15] \\
\hline $\begin{array}{c}\mathrm{Pt}_{1} @ \mathrm{Fe}-\mathrm{N}- \\
\mathrm{C}\end{array}$ & $\begin{array}{c}\mathrm{Pt}_{1}-\mathrm{O}_{2}-\mathrm{Fe}_{1}- \\
\mathrm{N}_{4}\end{array}$ & 2.1 & 0.4 & $1 \mathrm{M} \mathrm{KOH}$ & 120 & - & [16] \\
\hline $\mathrm{Pt} @ \mathrm{Ni} / \mathrm{NF}$ & Pt-NiO & - & 0.092 & $1 \mathrm{M} \mathrm{KOH}$ & 54 & 56 & [17] \\
\hline $\begin{array}{c}\mathrm{Ru} \\
\mathrm{SAs} @ \mathrm{PN}\end{array}$ & $\mathrm{Ru}-\mathrm{N}_{4}$ & 0.33 & 1 & $1 \mathrm{M} \mathrm{KOH}$ & 80 & - & [18] \\
\hline RuAu-0.2 & $\mathrm{Au}-\mathrm{Ru}_{x}$ & $\begin{array}{c}15.35 \\
\text { at. } \%\end{array}$ & 0.068 & $1 \mathrm{M} \mathrm{KOH}$ & 24 & 37 & [19] \\
\hline $\begin{array}{c}\mathrm{Ru} @ \text { NG- } \\
750\end{array}$ & $\mathrm{RuN}_{4} \mathrm{C}_{x}$ & 0.8 & - & $1 \mathrm{M} \mathrm{KOH}$ & 40 & 35.9 & [20] \\
\hline $\mathrm{Ru} / \mathrm{C}$ & $\mathrm{Ru}-\mathrm{C}$ & - & 0.25 & $1 \mathrm{M} \mathrm{KOH}$ & 142 & 48 & [21] \\
\hline
\end{tabular}


Table S3. Summary of single-atom electrocatalysts for the OER.

\begin{tabular}{|c|c|c|c|c|c|c|c|}
\hline Catalysts & $\begin{array}{c}\text { Metal } \\
\text { configu } \\
\text { ration }\end{array}$ & $\begin{array}{c}\text { Metal } \\
\text { content } \\
{[\text { wt. } \%]}\end{array}$ & $\begin{array}{l}\text { Loading } \\
{\left[\mathrm{mg} \mathrm{cm}^{-2}\right]}\end{array}$ & Electrolytes & $\begin{array}{c}\eta \\
{[\mathrm{mV}]}\end{array}$ & $\begin{array}{l}\text { Tafel slope } \\
{\left[\mathrm{mV} \mathrm{dec}^{-1}\right]}\end{array}$ & Reference \\
\hline SA-Ir@GS & $\mathrm{Ir}-\mathrm{N}_{3}$ & 0.89 & 0.004 & $1 \mathrm{M} \mathrm{KOH}$ & 418 & 57.2 & This work \\
\hline $\mathrm{IrO} 2$ & Ir-O & 100 & 0.004 & $1 \mathrm{M} \mathrm{KOH}$ & 420 & 75.9 & This work \\
\hline $\mathrm{Co}-\mathrm{Fe}-\mathrm{N}-\mathrm{C}$ & $\mathrm{Co}-\mathrm{Fe}$ & - & 0.6 & $1 \mathrm{M} \mathrm{KOH}$ & 309 & 37 & [22] \\
\hline $\mathrm{Co}-\mathrm{C}_{3} \mathrm{~N}_{4} / \mathrm{CNT}$ & $\begin{array}{l}\mathrm{Co}- \\
\mathrm{C}_{3} \mathrm{~N}_{4}\end{array}$ & 0.2 & 0.4 & $1 \mathrm{M} \mathrm{KOH}$ & 380 & 68.4 & {$[23]$} \\
\hline Co@NG-750 & $\mathrm{Co}-\mathrm{N}_{4}$ & 1.3 & 0.28 & $1 \mathrm{M} \mathrm{KOH}$ & 386 & 73 & {$[24]$} \\
\hline $\begin{array}{c}\mathrm{Fe}-\mathrm{N}_{4} \\
\mathrm{SAs} / \mathrm{NPC}\end{array}$ & $\mathrm{Fe}-\mathrm{N}_{4}$ & 1.96 & 2 & $1 \mathrm{M} \mathrm{KOH}$ & 43 & 95 & {$[25]$} \\
\hline $\mathrm{Ir} / \mathrm{NiO}$ & Ir-NiO & 18 & - & $1 \mathrm{M} \mathrm{KOH}$ & 215 & 38 & {$[26]$} \\
\hline $\mathrm{Ir}_{1} @ \mathrm{Co} / \mathrm{NC}$ & Ir-CoO & 2.2 & - & $1 \mathrm{M} \mathrm{KOH}$ & 260 & 163 & {$[12]$} \\
\hline $\mathrm{Mn}-\mathrm{NG}$ & $\mathrm{Mn}$ & 0.5 & - & $1 \mathrm{M} \mathrm{KOH}$ & 337 & 55 & [27] \\
\hline $\mathrm{Pt}_{1} @ \mathrm{Fe}-\mathrm{N}-\mathrm{C}$ & $\begin{array}{l}\mathrm{Pt}_{1}-\mathrm{O}_{2}- \\
\mathrm{Fe}_{1}-\mathrm{N}_{4}\end{array}$ & 2.1 & 0.4 & $0.1 \mathrm{M} \mathrm{KOH}$ & 310 & 62 & {$[16]$} \\
\hline $\mathrm{Pt} / \mathrm{NiO}$ & $\mathrm{Pt}-\mathrm{NiO}$ & 1 & 0.1 & $1 \mathrm{M} \mathrm{KOH}$ & 358 & 33 & {$[28]$} \\
\hline $\begin{array}{c}\mathrm{Ru} / \mathrm{CoFe}- \\
\mathrm{LDHs}\end{array}$ & $\begin{array}{l}\mathrm{Ru}- \\
\mathrm{CoFe}\end{array}$ & 0.45 & 2 & $1 \mathrm{M} \mathrm{KOH}$ & 198 & 39 & [29] \\
\hline Ru@NG-750 & $\mathrm{RuN}_{4} \mathrm{C}_{x}$ & 0.8 & - & $1 \mathrm{M} \mathrm{KOH}$ & 372 & 68 & {$[20]$} \\
\hline
\end{tabular}

Table S4. Summary of single-atom electrocatalysts for overall water splitting performance.

\begin{tabular}{cccc}
\hline Catalyst & Electrolyte & $\begin{array}{c}\text { Cell voltage at } 10 \\
\mathrm{~mA} \mathrm{~cm}^{-2}(\mathrm{~V} \text { versus } \\
\mathrm{RHE})\end{array}$ & Reference \\
\hline $\mathrm{SA}-\mathrm{Ir} @ \mathrm{GS}$ & $1 \mathrm{M} \mathrm{KOH}$ & 1.65 & This work \\
$\mathrm{Ir}_{1} / \mathrm{Co}_{0.8} \mathrm{Fe}_{0.2} \mathrm{Se}_{2} @ \mathrm{Ni}$ & $1 \mathrm{M} \mathrm{KOH}$ & 1.39 & {$[30]$} \\
foam & & & \\
$\mathrm{Ir}_{1} / \mathrm{Co}_{0.8} \mathrm{Fe}_{0.2} \mathrm{Se}_{2}$ & $1 \mathrm{M} \mathrm{KOH}$ & 1.48 & {$[30]$} \\
$\mathrm{Co}-\mathrm{MoS}_{2} / \mathrm{BCCF}-21$ & $1 \mathrm{M} \mathrm{KOH}$ & 1.55 & {$[31]$} \\
$\mathrm{Ir}_{1} @ \mathrm{Co} / \mathrm{NC}$ & $1 \mathrm{M} \mathrm{KOH}$ & 1.603 & {$[12]$} \\
$\mathrm{Ru} @ \mathrm{NG}$ & $1 \mathrm{M} \mathrm{KOH}$ & 1.65 & {$[20]$} \\
$\mathrm{Fe}-\mathrm{N}_{4} \mathrm{SAs} / \mathrm{NPC}$ & $1 \mathrm{M} \mathrm{KOH}$ & 1.67 & {$[25]$} \\
\hline
\end{tabular}




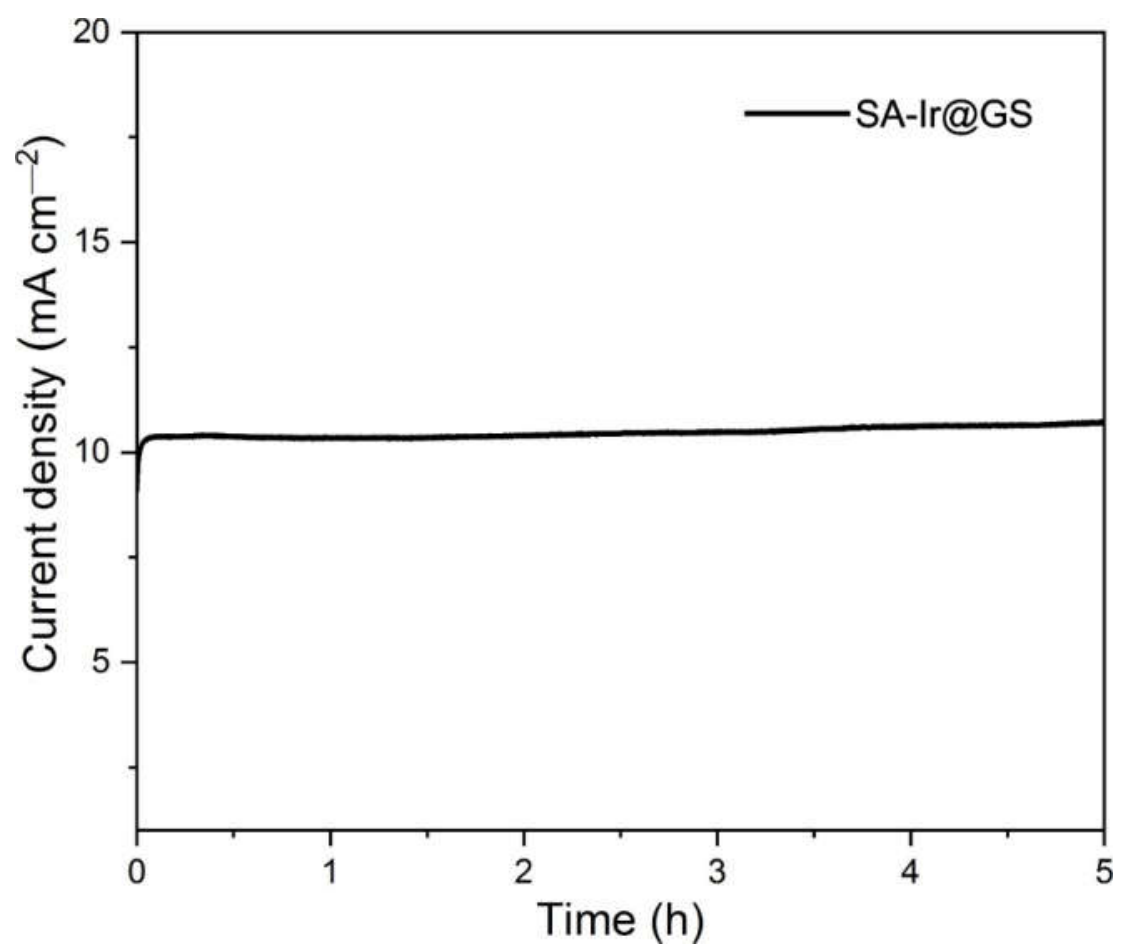

Figure S15. Stability test for SA-Ir@GS catalyst in 1м KOH at 1.65 V vs. RHE.

\section{cost for $1 \mathrm{~g}$ of SA-Ir@GS = 3.81€}

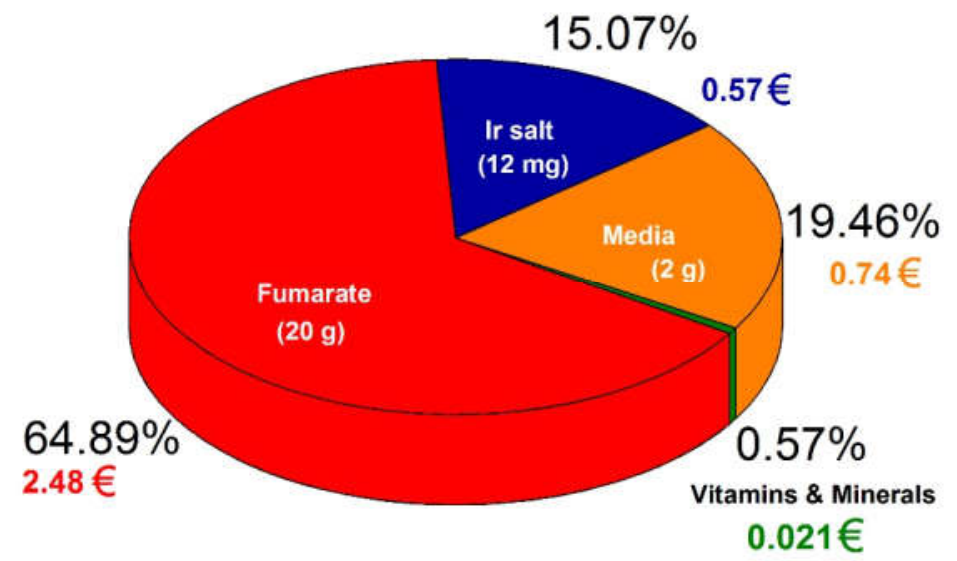

Figure S16. Cost estimate of raw chemicals used for the synthesis of 1 g of SA-Ir@GS catalyst. The media contains acetate $\left(0.82 \mathrm{~g} \mathrm{~L}^{-1}\right)$ as carbon source and electron donor. Fumarate was used as the electron acceptor for the generation of the initial culture of $G$. sulfurreducens to be used for the synthesis of SA-Ms. $\mathrm{IrCl}_{3} \cdot \mathrm{XH}_{2} \mathrm{O}$ was used as the precursor for Ir. 


\section{References}

[1] D. R. Bond, D. R. Lovley, Appl. Environ. Microbiol. 2003, 69, 1548; D. R. Lovley, R. C. Greening, J. G. Ferry, Appl. Environ. Microbiol. 1984, 48, 81.

[2] A. K. Poswal, A. Agrawal, A. K. Yadav, C. Nayak, S. Basu, S. R. Kane, C. K. Garg, D. Bhattachryya, S. N. Jha, N. K. Sahoo, AIP Conference Proceedings 2014, 1591, 649; S. Basu, C. Nayak, A. K. Yadav, A. Agrawal, A. K. Poswal, D. Bhattacharyya, S. N. Jha, N. K. Sahoo, Journal of Physics: Conference Series 2014, 493, 012032.

[3] G. Bunker, Introduction to XAFS: A Practical Guide to X-ray Absorption Fine Structure Spectroscopy, Cambridge University Press, Cambridge 2010; S. Kelly, D. Hesterberg, B. Ravel, Soil Science Society of America, Medison 2008, 387.

[4] M. Newville, B. Ravel, D. Haskel, J. J. Rehr, E. A. Stern, Y. Yacoby, Physica B: Condensed Matter 1995, 208-209, 154.

[5] M. J. Frisch, G. W. Trucks, H. B. Schlegel, G. E. Scuseria, M. A. Robb, J. R. Cheeseman, G. Scalmani, V. Barone, G. A. Petersson, H. Nakatsuji, X. Li, M. Caricato, A. V. Marenich, J. Bloino, B. G. Janesko, R. Gomperts, B. Mennucci, H. P. Hratchian, J. V. Ortiz, A. F. Izmaylov, J. L. Sonnenberg, Williams, F. Ding, F. Lipparini, F. Egidi, J. Goings, B. Peng, A. Petrone, T. Henderson, D. Ranasinghe, V. G. Zakrzewski, J. Gao, N. Rega, G. Zheng, W. Liang, M. Hada, M. Ehara, K. Toyota, R. Fukuda, J. Hasegawa, M. Ishida, T. Nakajima, Y. Honda, O. Kitao, H. Nakai, T. Vreven, K. Throssell, J. A. Montgomery Jr., J. E. Peralta, F. Ogliaro, M. J. Bearpark, J. J. Heyd, E. N. Brothers, K. N. Kudin, V. N. Staroverov, T. A. Keith, R. Kobayashi, J. Normand, K. Raghavachari, A. P. Rendell, J. C. Burant, S. S. Iyengar, J. Tomasi, M. Cossi, J. M. Millam, M. Klene, C. Adamo, R. Cammi, J. W. Ochterski, R. L. Martin, K. Morokuma, O. Farkas, J. B. Foresman, D. J. Fox, Wallingford, CT 2016.

[6] H. Fei, J. Dong, Y. Feng, C. S. Allen, C. Wan, B. Volosskiy, M. Li, Z. Zhao, Y. Wang, H. Sun, P. An, W. Chen, Z. Guo, C. Lee, D. Chen, I. Shakir, M. Liu, T. Hu, Y. Li, A. I. Kirkland, X. Duan, Y. Huang, Nat. Catal. 2018, 1, 63; N. H. Kwon, M. Kim, X. Jin, J. Lim, I. Y. Kim, N.-S. Lee, H. Kim, S.-J. Hwang, NPG Asia Materials $2018,10,659$.

[7] J. Rossmeisl, K. Dimitrievski, P. Siegbahn, J. K. Nørskov, J. Phys. Chem. C 2007, 111, 18821; Á. Valdés, Z. W. Qu, G. J. Kroes, J. Rossmeisl, J. K. Nørskov, J. Phys. Chem. C 2008, 112, 9872; J. K. Nørskov, T. Bligaard, A. Logadottir, S. Bahn, L. B. Hansen, M. Bollinger, H. Bengaard, B. Hammer, Z. Sljivancanin, M. Mavrikakis, Y. Xu, S. Dahl, C. J. H. Jacobsen, J. Catal. 2002, 209, 275; J. Rossmeisl, Z. W. Qu, H. Zhu, G. J. Kroes, J. K. Nørskov, J. Electroanal. Chem. 2007, 607, 83; J. Rossmeisl, A. Logadottir, J. K. Nørskov, Chem. Phys. 2005, 319, 178.

[8] H. Fei, J. Dong, M. J. Arellano-Jiménez, G. Ye, N. Dong Kim, E. L. G. Samuel, Z. Peng, Z. Zhu, F. Qin, J. Bao, M. J. Yacaman, P. M. Ajayan, D. Chen, J. M. Tour, Nat. Commun. 2015, 6, 8668.

[9] J. Mao, C.-T. He, J. Pei, W. Chen, D. He, Y. He, Z. Zhuang, C. Chen, Q. Peng, D. Wang, Y. Li, Nat. Commun. 2018, 9, 4958.

[10] L. Cao, Q. Luo, W. Liu, Y. Lin, X. Liu, Y. Cao, W. Zhang, Y. Wu, J. Yang, T. Yao, S. Wei, Nat. Catal. 2019, 2, 134.

[11] Y. Pan, S. Liu, K. Sun, X. Chen, B. Wang, K. Wu, X. Cao, W.-C. Cheong, R. Shen, A. Han, Z. Chen, L. Zheng, J. Luo, Y. Lin, Y. Liu, D. Wang, Q. Peng, Q. Zhang, C. Chen, Y. Li, Angew. Chem. Int. Ed. 2018, 57, 8614.

[12] W.-H. Lai, L.-F. Zhang, W.-B. Hua, S. Indris, Z.-C. Yan, Z. Hu, B. Zhang, Y. Liu, L. Wang, M. Liu, R. Liu, Y.-X. Wang, J.-Z. Wang, Z. Hu, H.-K. Liu, S.-L. Chou, S.-X. Dou, Angew. Chem. Int. Ed. 2019, 58, 11868.

[13] Y. Qu, B. Chen, Z. Li, X. Duan, L. Wang, Y. Lin, T. Yuan, F. Zhou, Y. Hu, Z. Yang, C. Zhao, J. Wang, C. Zhao, Y. Hu, G. Wu, Q. Zhang, Q. Xu, B. Liu, P. Gao, R. You, W. Huang, L. Zheng, L. Gu, Y. Wu, Y. Li, Journal of the American Chemical Society 2019, 141, 4505.

[14] K. Jiang, B. Liu, M. Luo, S. Ning, M. Peng, Y. Zhao, Y.-R. Lu, T.-S. Chan, F. M. F. de Groot, Y. Tan, Nat. Commun. 2019, 10, 1743.

[15] H. Zhang, P. An, W. Zhou, B. Y. Guan, P. Zhang, J. Dong, X. W. Lou, Science Advances 2018, 4, eaao6657.

[16] X. Zeng, J. Shui, X. Liu, Q. Liu, Y. Li, J. Shang, L. Zheng, R. Yu, Adv. Energy Mater. 2018, 8, 1701345. 
[17] Z.-J. Chen, G.-X. Cao, L.-Y. Gan, H. Dai, N. Xu, M.-J. Zang, H.-B. Dai, H. Wu, P. Wang, ACS Catalysis 2018, 8, 8866.

[18] J. Yang, B. Chen, X. Liu, W. Liu, Z. Li, J. Dong, W. Chen, W. Yan, T. Yao, X. Duan, Y. Wu, Y. Li, Angew. Chem. Int. Ed. Engl. 2018, 57, 9495.

[19] C.-H. Chen, D. Wu, Z. Li, R. Zhang, C.-G. Kuai, X.-R. Zhao, C.-K. Dong, S.-Z. Qiao, H. Liu, X.-W. Du, Adv. Energy Mater. 2019, 9, 1803913.

[20] L. Bai, Z. Duan, X. Wen, R. Si, Q. Zhang, J. Guan, ACS Catalysis 2019, 9, 9897.

[21] Q. Lu, A. L. Wang, Y. Gong, W. Hao, H. Cheng, J. Chen, B. Li, N. Yang, W. Niu, J. Wang, Y. Yu, X. Zhang, Y. Chen, Z. Fan, X. J. Wu, J. Chen, J. Luo, S. Li, L. Gu, H. Zhang, Nat Chem 2018, 10, 456.

[22] L. Bai, C.-S. Hsu, D. T. L. Alexander, H. M. Chen, X. Hu, Journal of the American Chemical Society 2019, 141, 14190.

[23] Y. Zheng, Y. Jiao, Y. Zhu, Q. Cai, A. Vasileff, L. H. Li, Y. Han, Y. Chen, S.-Z. Qiao, Journal of the American Chemical Society 2017, 139, 3336.

[24] Q. Zhang, Z. Duan, M. Li, J. Guan, Chem. Commun. 2020, 56, 794.

[25] Y. Pan, S. Liu, K. Sun, X. Chen, B. Wang, K. Wu, X. Cao, W. C. Cheong, R. Shen, A. Han, Z. Chen, L. Zheng, J. Luo, Y. Lin, Y. Liu, D. Wang, Q. Peng, Q. Zhang, C. Chen, Y. Li, Angew. Chem. Int. Ed. Engl. 2018, $57,8614$.

[26] Q. Wang, X. Huang, Z. L. Zhao, M. Wang, B. Xiang, J. Li, Z. Feng, H. Xu, M. Gu, Journal of the American Chemical Society 2020, 142, 7425.

[27] J. Guan, Z. Duan, F. Zhang, S. D. Kelly, R. Si, M. Dupuis, Q. Huang, J. Q. Chen, C. Tang, C. Li, Nat. Catal. 2018, 1, 870.

[28] C. Lin, Y. Zhao, H. Zhang, S. Xie, Y.-F. Li, X. Li, Z. Jiang, Z.-P. Liu, Chemical Science 2018, 9, 6803.

[29] P. Li, M. Wang, X. Duan, L. Zheng, X. Cheng, Y. Zhang, Y. Kuang, Y. Li, Q. Ma, Z. Feng, W. Liu, X. Sun, Nat. Commun. 2019, 10, 1711.

[30] Z. Zhang, C. Feng, C. Liu, M. Zuo, L. Qin, X. Yan, Y. Xing, H. Li, R. Si, S. Zhou, J. Zeng, Nat. Commun. 2020, 11, 1215.

[31] Q. Xiong, Y. Wang, P.-F. Liu, L.-R. Zheng, G. Wang, H.-G. Yang, P.-K. Wong, H. Zhang, H. Zhao, Adv. Mater. 2018, 30, 1801450. 